\title{
The effects of a walking intervention on self-efficacy for coping with cancer and quality of life among cancer patients during treatment
}

\author{
Sean J. Fitzpatrick \\ West Virginia University
}

Follow this and additional works at: https://researchrepository.wvu.edu/etd

\section{Recommended Citation \\ Fitzpatrick, Sean J., "The effects of a walking intervention on self-efficacy for coping with cancer and quality of life among cancer patients during treatment" (2010). Graduate Theses, Dissertations, and Problem Reports. 2999. \\ https://researchrepository.wvu.edu/etd/2999}

This Thesis is protected by copyright and/or related rights. It has been brought to you by the The Research Repository @WVU with permission from the rights-holder(s). You are free to use this Thesis in any way that is permitted by the copyright and related rights legislation that applies to your use. For other uses you must obtain permission from the rights-holder(s) directly, unless additional rights are indicated by a Creative Commons license in the record and/ or on the work itself. This Thesis has been accepted for inclusion in WVU Graduate Theses, Dissertations, and Problem Reports collection by an authorized administrator of The Research Repository @ WVU. For more information, please contact researchrepository@mail.wvu.edu. 
The Effects of a Walking Intervention on Self-Efficacy for Coping with Cancer and Quality of Life among Cancer Patients during Treatment

\author{
Sean J. Fitzpatrick
}

Thesis submitted to the College of Physical Activity and Sport Sciences at West Virginia University in partial fulfillment of the requirements for the degree of

\author{
Master of Science \\ in \\ Sport and Exercise Psychology \\ Samuel Zizzi, Ed.D., Chair \\ Sean Bulger Ed.D \\ Irene Tessaro, DrPH
}

Morgantown, WV

2010

Keywords: Cancer, Exercise, Physical Activity, Walking, Self-Efficacy for Coping with Cancer, Quality of Life 


\begin{abstract}
The Effects of a Walking Intervention on Self-Efficacy for Coping with Cancer and Quality of Life among Cancer Patients during Treatment
\end{abstract}

\title{
Sean J. Fitzpatrick
}

Cancer affects millions of Americans each year and as such there are numerous individuals fighting this disease at any time. Though strides are being made every day to better treat and hopefully one day cure this disease, the needs of these patients is a current area receiving a high amount of attention (Meadows et al, 1998). There are numerous positive outcomes associated with physical activity including attenuating cancer side-effects. As such, exercise during cancer treatment has recently received attention within the literature.

The current study aimed to test a novel walking intervention utilizing pedometers to increase physical activity. In addition, the relationships between physical activity and selfefficacy for coping with cancer and quality of life were studied. Ten $(N=10)$ individuals were enrolled within the investigated. On average, individuals took 34,962.67 (SD =10,635.49). steps per week throughout the six-week study. Due to the low number of individuals who completed the intervention, relationships between physical activity and the dependant variables are hard to quantify. However, when individuals were looked at in a single-subject fashion, a positive relationship between physical activity and psycho-social variables seemed to exist. Interviews were also conducted $(n=4)$ and themes of motivation and control arose from these interviews. Though the numerous limitations of the study prevented the use of adequate statistical techniques to quantify relationships among variables, the findings of this study point to the idea that increased physical activity is advantageous to cancer patients. Suggestions based on the numerous challenges of the current study are also included. 


\section{ACKNOWLEDGEMENTS}

There are many people that I need to thank for their help in making this project a reality. First and foremost to doctors Sean Bulger and Irene Tessaro, thank you for your unwavering support and your constant understanding and flexibility.

To Dr. Zizzi, I honestly do not know how I would have started let alone finished this project without your help. Throughout the whole process you had an uncanny ability to know when to push me when I needed pushed and when to let me be when I needed it. I hope when I am one day in your shoes I can be half the mentor that you've been and continue to be.

To Dr. Jame Abraham, Angie Price, and Christine Tringes, thank you for your willingness to allow me recruit your patients. I've spent entirely too much of my life in hospitals and I've been around few professionals that treat their patients with more respect and are more endeared by those that care for than you three.

To Kim and Pete, thank you for help with the qualitative portion of this study. I know that my directions were a little fuzzy, but you both did a great job and your work may be leading me to a qualitative dissertation in this area.

To all my friends and colleagues, thank you for always being there for a laugh, a lunch, or just to hear to me rant. The most valuable thing about my graduate experience has been the friends I've made.

To Colleen, thank you for always supporting me and for having tirelessly and selflessly dealing with everything that has happened the past few years. You've managed to handle the lion's share of everything while I've been away and have done so with elegance and class. To SJ2, I was only lucky enough to have you around for the tail-end of this project, but the support you gave and continue to give has meant the world to me. I don't tell you enough, but I am incredibly lucky to have you in my life. 


\section{DEDICATION}

Finishing this project has been one of the hardest, most time consuming and frustrating endeavors' of my still somewhat yet young life. Hardly anything went to plan: the IRB took over three months to be approved; this study was the one study within the College of Physical Activity and Sport Sciences to be "randomly" selected for a in-depth follow-up by the IRB; recruitment was less than desirable to say the least; and these are just some of the things that happened in the academic realm of my life. On the personal side during this time my father was diagnosed with leukemia, my mother's nine year battle with breast cancer came to end, and my father too passed away after his two year fight. To put it bluntly the four years that this study took to complete sucked.

I do not think that most people realize that I was offered the opportunity to not finish this study. After losing my mother I found it hard to re-enter the cancer center and speak with and recruit participant who were afflicted with cancer. When I lost my father, I was told that if I need to go a different direction I could. I thought long and hard about this offer. Obviously I ended up staying the course and finishing what I started. This was not easy. Spending hours working on a study that is focused on the disease that took both of my parents was not easy. But it was something I felt compelled to do.

Though my relationships with parents were much shorter than I had ever thought they would be I learned a great deal from both of them. These lessons are too many to count and too intangible and valuable to properly describe in words. However, it was one lesson that both of them taught me that carried me through the completion of this project. Both of my parents taught me what true strength was. For nine years, unbeknownst me at the time, my mother was told time and time again that she had little chance of living more than few months. Each time she heard this, she told the doctors they were wrong, and time and time again they were. My father's fight was very different. Unlike my mother my father was told with certainty that he had days to live. At first he was afraid, but as the time drew nearer and his physical strength left him, he showed what true strength was. During the time when he deserved to receive the most comfort, he somehow, without many words or movements put those around him, including me, in comfort.

I finished this project not for myself; I finished this project because I remember how proud both my parents were that I choose to do a study that involved cancer patients. To my mother and father whom I will love forever, I did this for you, and I know that somewhere you're both proud. 
Table of Contents

pg\#

Introduction 1

$\begin{array}{ll}\text { Methods } & 8\end{array}$

$\begin{array}{lr}\text { Participants and recruitment } & 9\end{array}$

$\begin{array}{lr}\text { Procedures } & 9\end{array}$

$\begin{array}{ll}\text { Instrumentation } & 10\end{array}$

$\begin{array}{ll}\text { Physical activity } & 10\end{array}$

Self-efficacy for coping with cancer $\quad 11$

Quality of life $\quad 12$

$\begin{array}{ll}\text { Participant interviews } & 13\end{array}$

$\begin{array}{ll}\text { Data analyses } & 14\end{array}$

$\begin{array}{ll}\text { Results } & 14\end{array}$

$\begin{array}{ll}\text { Pre-test data } & 15\end{array}$

Self-efficacy for coping with cancer $\quad 15$

Quality of life $\quad 15$

$\begin{array}{ll}\text { Weekly data } & 16\end{array}$

$\begin{array}{ll}\text { Step-counts } & 16\end{array}$

Global health and QOL 16

$\begin{array}{ll}\text { Post-test data } & 16\end{array}$

Self-efficacy for coping with cancer $\quad 16$

Quality of life $\quad 16$

$\begin{array}{ll}\text { Individual case analyses } & 17\end{array}$

$\begin{array}{ll}\text { Participant } 2 & 17\end{array}$ 
$\begin{array}{ll}\text { Participant } 6 & 18\end{array}$

$\begin{array}{ll}\text { Participant } 7 & 18\end{array}$

$\begin{array}{ll}\text { Participant } 8 & 19\end{array}$

$\begin{array}{ll}\text { Qualitative Data } & 20\end{array}$

Interview one: Participant 2

Interview two: Participant 5 22

Interview three: Participant 4

Interview four: Participant $10 \quad 24$

$\begin{array}{ll}\text { Summary } & 26\end{array}$

$\begin{array}{ll}\text { Discussion } & 26\end{array}$

$\begin{array}{ll}\text { Limitations } & 30\end{array}$

Summary and future direction $\quad 32$

$\begin{array}{ll}\text { References } & 34\end{array}$

List of Appendixes

$\begin{array}{lll}\text { APPENDIX A } & \text { Review of literature }\end{array}$

References $\quad 72$

$\begin{array}{lll}\text { APPENDIX B } & \text { CBI } & 78\end{array}$

$\begin{array}{lll}\text { APPENDIX C } & \text { EO-QOL }\end{array}$

$\begin{array}{lll}\text { APPENDIX D } & \text { Participants' tracking sheet }\end{array}$

$\begin{array}{lll}\text { APPENDIX E } & \text { Interview cover letter }\end{array}$

$\begin{array}{lll}\text { APPENDIX F } & \text { Interview script } & 84\end{array}$ 


\section{List of Tables and Figures}

$\begin{array}{ll}\text { Table 1: CBI scores } & 42\end{array}$

Table 2: EO-QOL functioning scores 43

Table 3: Weekly step counts, QOL, and global health scores 44

Figure 1: Participant 2's steps 45

Figure 2: Participant 2's QOL and global health 45

Figure 3: Participant 6’s steps 46

Figure 4: Participant 6's QOL and global health 46

$\begin{array}{ll}\text { Figure 5: Participant 7's steps } & 47\end{array}$

Figure 6: Participant 7's QOL and global health 47

$\begin{array}{ll}\text { Figure 7: Participant 8's steps } & 48\end{array}$

Figure 8: Participant 8's QOL and global health 48

Figure 9: Combined participants’ steps 49

Figure 10: Combined participants' QOL and global health 49 


\section{INTRODUCTION}

In 2008 it was estimated that the annual "costs" of cancer was just over 228 billion dollars (Ahmedin, Siegel, Ward, Hao, Xu, \& Thun, 2009). One quarter of all American deaths are cancer related; with over half a million individuals dying each year, or more than 1,500 a day (American Cancer Society, 2007). It is estimated that each year there are 1.5 million new cases of cancer, and in West Virginia that yearly number stands a little over 10,000 people (Ahmedin et al, 2008). On any given day there are thousands of Americans receiving many forms of cancer treatment. The good news is that 5-year survival figures have risen to 66 percent (American Cancer Society, 2007). In 2003 there were an estimated ten and half million cancer survivors living in the US, and with the overall risk of developing some form of cancer just under 1 in 2 for men, and slightly more than 1 in 3 for women, cancer is a disease that touches almost every person in America (American Cancer Society, 2007).

Until the day comes when a cure is found there will continue to be a need for further research. While the majority of research goes into new treatment/detection measures, the needs of the actual patients undergoing treatment and the unique needs of the survivors are starting to receive more attention (Meadows et al., 1998). The cancer treatment process can be a challenging time for cancer patients and their loved ones (McBride, Clipp, Peterson, Lipkus, \& Demark-Wahnefried, 2000). The National Cancer Institute lists 22 different side-effects that might arise with cancer treatments (National Cancer Institute, 1999). Fatigue, nausea, and depression make up just a small sample of the many side-effects that may occur throughout treatment.

Since the treatment process can be so daunting, many researchers have looked at ways to make this process more manageable for cancer patients. In fact, the Office of Cancer 
Survivorship has stated that the need for intervention studies to look at ways to prevent or diminish adverse outcomes or promote healthy behaviors is one of the six key areas for research development (Rowland, Aziz, Tesauro, \& Feuer, 2001). One area that has started to receive considerable attention is the use of exercise during the cancer treatment process.

\section{Exercise Interventions}

With increased fatigue levels and, at times, a persistent feeling of sickness, exercise might be the last thing on a patient's mind. In fact, Stevinson and Fox (2006) reported that even the most committed and serious exercisers did not think to attempt exercise during their treatment process. There are a number of potential reasons why patients may not seek out physical activity (PA) during the initial treatment process. One of the main reasons may simply be a lack of knowledge regarding the potential benefits of PA during this time. It is theorized that even among oncology staff the awareness and acceptance of exercise during treatment is lacking (Stevinson \& Fox).

Cancer patients face unique physical, psychological, and emotional barriers (Perna, Craft, Carver, \& Antoni, 2008). Many patients face a persistent sense of tiredness, or fatigue, which stems from their treatment process and interferes with many of life's normal daily functions (Mock et al, 2003). Perna and colleagues found that fatigue and negative affect are correlated, suggesting that fatigue may be both a physical and emotional construct. In addition to fatigue, cancer patients deal with a number of stressors, be it the physical stress in the forms of sideeffects such as nausea, or the psychological stress that accompanies a cancer diagnosis.

Almost unequivocally, however, patients who join an exercise intervention during treatment have found these interventions to be tolerable (Conn, Hafdahl, Porock McDaniel \& Nielsen, 2006; Losito, Murphy, \& Thomas, 2006; Schmitz, Holtzman, Courneya, Masse, Duval, 
$\&$ Kane, 2005). In their review of studies, Schmitz and colleagues found that the average dropout rate for exercise interventions taking place during treatment was only $11.5 \%$; this is promising when considering the increased likelihood of subjects withdrawing for health reasons that inherently accompanies working with this population. This low attrition rate is even more impressive when contrasted with a comparable population. It has been widely established that exercise is strongly correlated with increased survival rates for individuals who have had a cardiac episode (i.e. myocardial infarction), yet the average adherence rate for cardiac rehabilitation programs is around 30\% (Daly et al, 2002). The impressive adherence rates of many exercise interventions might be attributed to the mindset of many cancer patients.

The actual diagnosis is often thought of as a "teachable moment"-patients are often looking for ways to improve their health (Demark-Wahnefried et al, 2003, McBride et al, 2000). When asked about the ideal time for interventions, patients favored the initial treatment period, and their receptivity was reported as being higher during this initial period (within the first 6 months of diagnosis) (Demark-Wahnefried, Peterson, McBride, Lipkus, \& Clipp, 2000). As a whole, these individuals may be seeking ways to regain control of their health and they may possess a need or desire to implement a behavior they view as healthy (Mock et al, 2005). Furthermore, even though these individuals' physical capacities do become diminished, in most cases patients can tolerate light to moderate PA (van Weert, Hoekstra-Weebers, May, Korstjens, Ros \& van der Schans 2008).

Throughout the literature many positive outcomes associated with increased PA during cancer treatment have been found. First and foremost, increased levels of PA reduces the risk for several common cancers which is of even greater importance with cancer patients/survivors since they are at an elevated risk for development of new cancers (Holmes, Chen, Feskanich, Kroenke, 
\& Colditz, 2005; Vallance, Courneya, Plotnikoff, \& Mackey, 2008). This reason alone would be enough to provide credence to promoting exercise, but there are a number of additional positive findings. For instance, using meta-analysis data, interventions have a moderate weighted means effect size of .51 on aerobic capacity, which is encouraging since many patients find that their aerobic capacity diminishes during chemotherapy or radiation (van Weert et al, 2008). In a study of breast cancer patients undergoing either chemotherapy or radiation $(n=52)$, it was found that those who exercised more frequently experienced significantly less fatigue $(r=0.52)$ (Mock et al, 2001). Similarly, exercise as been found to help ease the often severe side effects experienced during treatment (Mustian et al, 2006).

Most exercise interventions with cancer patients have used light to moderate exercise; with walking being the most common modality of activity (van Weert et al, 2008; McNeely et al, 2006; Knols et al, 2005; Stevinson, Lawlor, \& Fox, 2004). Some studies have included resistance training to increase VO2max, lean body mass, and muscle strength (Herrero et al, 2006 Nieman et al, 1995). In a review of breast cancer studies, Courneya (2003) found that exercise had significant and beneficial effects on exercise capacity, body weight and composition, and physical well-being. A study with individuals who had stomach cancer surgery found that exercise was the only significant factor that positively affected natural killer cell cytotoxic activity, which is often claimed to be the immune surveillance cell for the body's defense against cancer (Na, Kim, Kim, Ha, \& Yoon, 2000).

Previous research has looked at a diverse catalog of outcomes, both psychological and physiological, that may be related to increased PA during the cancer treatment process. It is not within the scope of this paper to comprehensively explore all of these topics. Instead, two possible outcomes of PA will be discussed: self-efficacy and quality of life (QOL). 


\section{Self-Efficacy}

As briefly mentioned earlier, many of the studies that exist in the field of exercise and cancer have aimed to investigate exercise's effects on physiological outcomes. While these outcomes are indeed important and deserve further investigation, psychological variables warrant study as well. One such psychological variable that has not yet been an outcome for exercise interventions with this population, is self-efficacy. Self-efficacy is the belief that one can deal with the situations and dilemmas they are faced with, and is an important factor in overcoming any obstacle (Bandura, 1986). Self-efficacy is not a broad construct; instead individuals possess self-efficacy for different tasks and challenges. A person may possess a high level of selfefficacy to be physically active, for example, but a low self-efficacy for learning computer skills. It is believed that individuals with a higher disease-related self-efficacy, or their belief in their abilities to deal with their illness, have more realistic goals and lower levels of depression and anxiety (Tennstedt, 2000). This hypothesis has been tested with diabetes patients (Norris, Engelgau, \& Narayan, 2001;Kara, van der Bijl, Shortridge-Baggett, Asti, \& Erguney, 2006), where a positive relationship has been found between self-efficacy and health behaviors. Within the HIV literature, low self-efficacy has been shown to be a predictor of non-adherence with medication (Johnson, Gamarel, \& Rose, 2006; Johnson et al, 2003). Self-efficacy is equally important with cancer patients (Kreitler, Peleg, \& Ehrenfeld, 2007; Merluzzi, \& Martinez Sanchez, 1997b) whereas self-efficacy has been shown to be positively related to quality of life (Cunningham, Lockwood, \& Cunningham, 1991; Lev \& Owen, 2001). In addition, within a sample of patients with head and neck cancer, higher levels of self-efficacy were related to longer rates of survival and lower levels of cancer reoccurrence (De Boer et al, 1998). 
An important aspect of any disease-related self-efficacy is the patient's sense of control and involvement in the treatment process (Tennstedt, 2000). Since the cancer diagnosis often serves as a time when patients feel a loss of control, helping them to develop ownership over their continued health through the promotion of PA might serve as way to increase their selfefficacy towards dealing with the disease (Demark-Wahnefried et al, 2003). Within the PA literature, it has been hypothesized that many positive psychological outcomes are associated with raised levels of self-efficacy. Individuals feel a sense of accomplishment as they engage in exercise and experience fitness gains, which raises self-efficacy, which then in turns raise selfconfidence (Leith, 2002). Since cancer patients are often noticing their physical capacities diminishing, exercise, even at light to moderate levels, can not only increase self-efficacy through sense of accomplishment but it can also increase an individual's physical well-being which may raise self-efficacy even further (van Weert et al, 2008). There is no published research available using self-efficacy for coping with cancer as an outcome variable in an exercise intervention.

Quality of Life

Quality of life (QOL) is a broad construct, consisting of an individual's sense of wellbeing. This sense of well-being contains many different components, including physical, psychosocial, spiritual, and economic factors (Jordhoy et al, 2007). QOL is a subjective construct and it is affected by the individual's interpretations of their own goals, expectations, and values in regards to their present life status (Graves, 2003). Although QOL is one of the most widely studied outcomes in cancer research, there is little consensus on the best way to measure this multifaceted construct (Jordhoy et al). For this document, unless otherwise specified, QOL will 
be defined as the patient's assessment of their physical, psychological, and social functioning (Aaronson et al, 1993).

As to be expected, QOL decreases for most patients as they begin treatment (Valenti et al, 2008). In a study of 338 patients with colon cancer, Gall and colleagues noted that during treatment the median level of physical QOL for their subjects (39.95-45.57) was below the healthy population average (50). At both one and two year follow-up dates, patients' scores rose, though it should be noted that the median ranges for the physical component never reached a level where they reached the average score of 50. Valenti and colleagues work produced similar results. Within a sample of 212 female breast cancer survivors, all measured components of QOL were found to be lower during active treatment. In particular, the physical-component score rose from an average of $53.45(\mathrm{SD}=16.02)$ during treatment to $59.83(\mathrm{SD}=16.34)$ when no active treatment was present (the QOL measure for this study differs from the previous one so a score of 50 does not represent the healthy population average). They also found that psychological component scores rose more than three points.

In addition to studying the overall trends of QOL, Valenti and colleagues (2008) looked at the relationship between QOL and PA. They hypothesized that since physical functioning often makes up a large component of QOL those who were more physically active and theoretically possessed greater physical functioning would have higher levels of QOL. It was found that during treatment a positive relationship existed between physical QOL and moderate levels of activity $(r=0.28 p<0.05)$. This relationship was even stronger for strenuous exercise $(r=0.41 p<0.01)$. These findings were similar to those that Dr. Mock and her team (2001) observed in their study of 52 female breast cancer patients. All the participants were undergoing either chemotherapy or radiation treatment and were randomly assigned to a six-week walking 
program or to usual care. Individuals who exercised at least 90 minutes a day three or more days a week had higher levels of QOL and had lower levels of emotional distress. Individuals who were in the low activity group saw their physical QOL scores drop 48\% during treatment ( $p=$ $0.00)$, while those in the higher activity group only saw their scores drop $16 \%(p=0.02)$.

In her 2003 meta-analysis Kristi Graves used Social Cognitive Theory as a framework for understanding QOL. Graves found many instances where self-efficacy, one of the most influential components of Social Cognitive Theory was found to influence QOL. Without intervention both of these constructs, self-efficacy and QOL were found to decrease over time. Grave's hypothesized that increased self-efficacy can affect QOL in a number of ways, be it through an increased sense of accomplishment which can lead the patient to overcome obstacles they thought they couldn't achieve (i.e. returning to work), or through an increase in confidence which can aid in social interactions - which can directly affect QOL. Regardless of the mechanisms by which they are connected, QOL and self-efficacy are very much related.

These two psychosocial variables, self-efficacy for coping with cancer and QOL are important domains for cancer patients. Exercise interventions with cancer patients have come to be seen as beneficial and worthwhile and exercise is believed to potentially possess many advantageous outcomes including increased QOL. Though some believe that these two constructs are interrelated, self-efficacy for coping with cancer has never been an outcome of a study utilizing exercise interventions.

\section{METHODS}

The main purpose of this study was to investigate the effects of a novel walking intervention on cancer patients' levels of PA during their adjunct treatment process. A secondary 
purpose of the proposed study was to investigate the effects of PA on two outcome measuresself-efficacy for coping with cancer and QOL.

\section{Participants and Recruitment}

The study aimed to recruit 50 patients from a local cancer center. To be eligible for inclusion, participants must have been first time cancer patients undergoing their first regimen of adjunct treatment. In addition, participants needed to be between the ages of 30 and 65 . This age limit resembled that of other similar studies (Conn, Hafdahl, Porock, McDaniel, \& Nielsen, 2006).

Using a sample of convenience, individuals were approached for inclusion in the study during their visits to the Mary Babb Randolph Cancer Center. All participants $(n=10)$ were approached by the researcher and if they consented to the study they were enrolled immediately. All pre-test materials and documentation were filled out at this time. Their involvement in the study began on the Monday following their consent to take part in the project. This standardized approach made it easier for individuals to track their walking data across six weeks (Monday Sunday for each week).

\section{Procedures}

The original proposed study sought to utilize a two-group repeated-measures design over. This design was chosen as it is frequently used for the observation of changes from pre-test to post-test between two groups (Dugard \& Todman, 1995). The design was going to be utilized to investigate the effects of the independent variable: a walking intervention, on the dependent variables: levels of PA, self-efficacy for coping with cancer and QOL. 
Necessary approval from the Institutional Review Board of both West Virginia University and the Mary Babb Randolph Cancer was sought before any subjects were approached. As was stated earlier, upon individuals' recruitment individuals filled out pre-test data for both self-efficacy for coping with cancer and QOL. Participants were then e-mailed the first Sunday after they enrolled as a reminder to wear their pedometer and to start tracking their daily steps. All participants were then e-mailed the next Sunday with a prompt to visit a study specific web-site to input their PA levels for the week and to answer two general QOL questions. The researcher was notified automatically each time someone provides data to the web-site. Since the original design called for a control and experimental group, individuals who were placed randomly into the control group were simply thanked for providing data while those in the experimental group received the intervention which was a new step-count goal of a $15 \%$ increase for the next week via an email from the researcher. This pattern continued for the next five weeks.

After an individual's sixth and final input of data, the participant was e-mailed thanking them for their help and were asked to visit a web-site to fill out electronic copies of post-test instruments.

\section{Instrumentation}

Physical activity. For the purposes of this study, PA was quantified as number of steps taken in one week's time. To calculate this statistic each participant received a pedometer. The pedometer utilized was the Accusplit Eagle 170 Deluxe Activity Pedometer. This particular pedometer has been used in many research settings (i.e. Berry, Savoye, Melkus, \& Grey, 2007; Zizzi et al, 2006). To aid in the calculation of weekly step count totals, each participant received a daily step-tracking sheet. This sheet also provided instruction on the operation of the 
pedometer. In addition, upon recruitment the researcher demonstrated how to operate the pedometer.

Self-efficacy for coping with cancer. Self-efficacy for coping with cancer was assessed using the Cancer Behavior Inventory (Version 2.0) (CBI; Merluzzi et al, 2001; see Appendix B). The original CBI was created in conjunction with health care professionals, family members of cancer patients, existing coping literature, and the authors' professional experience counseling cancer patients (Merluzzi and Martinez Sanchez, 1997a). The original measure had 51 items measuring six factors and was scored with a nine-point confidence rating scale. The revision was made to include the new factor which the authors' felt went overlooked in the original (seeking and understanding medical information), and to decrease the length of the CBI to ease in the administration procedures.

The CBI v.2 is made up of 33 items that measure self-efficacy for coping with cancer on seven different factors. There are five items for six factors, and three items for the seventh. Each item asks the patient to judge how confident they are in accomplishing a given task. Scores can range from 1 "not at all confident", to 9 "totally confident" for each item. The seven different factors are $\{$ sample item\}: (1) maintenance of activity and independence \{Maintaining work activity\}; (2) seeking and understanding medical information \{Asking nurses questions\}; (3) stress management $\{$ Remaining relaxed through treatment (chemotherapy, radiation) $\}$; (4) coping with treatment related side effects \{Coping with physical changes\}; (5) accepting cancer/maintaining a positive attitude Accepting that I have cancer\}; (6) affective regulation \{Expressing negative feelings about cancer\}; and (7) seeking social support $\{$ Sharing feelings of concern $\}$. 
Each factor in the CBI v. 2 is scored by summing the items for that factor. For comparisons across factors, the sum can be divided by the number of items in each scale. For any missing data, the authors suggest substituting the mean score for that factor in place of the missing data. A total score can also be found by adding up all the items in the survey (Merluzzi, Narin, \& Martinez Sanchez, 1999).

During its creation steps were taken to assure the instrument was both reliable and valid. The overall internal consistency for the second version of the CBI is 0.94 , which is only 0.02 lower than the original longer version. The Kaiser-Meyer-Olkin (KMO) measure of sampling adequacy for the $\mathrm{CBI}$ is 0.86 . The $\mathrm{KMO}$ scores range from zero to one, and is a measure used to determine the appropriateness of using factor analysis. Any score below 0.5 means that factor analysis is not appropriate, while scores above that threshold mean the opposite (Foulger, 2004). The seven-factor model of the CBI v. 2 accounts for $63.4 \%$ of the variance. Each of the seven factors tested out with alpha levels above 0.79 (Merluzzi et al, 2001).

Quality of life. Quality of life was measured using the European Organization for the Research and Treatment of Cancer Quality of Life Questionnaire (EO-QOL) (Aaronson et al, 1993). The EO-QOL is currently in its third version and is one of the most widely used measures for QOL all over the world. Since its creation, the EO-QOL has been translated and validated into 81 different languages and used in over 3,000 studies worldwide. The instrument consists of 30 different questions covering physical functioning (five items), role functioning (two items), cognitive functioning (two items), emotional functioning (four items), social functioning (two items), global health status (two items), fatigue (three items), nausea and vomiting (two items), pain (two items), and six single items (short of breath, trouble sleeping, lack of appetite, constipation, diarrhea, and financial problems) (see Appendix C). The first five items on the 
scale are general questions about functioning (e.g. "Do you have any trouble taking a long walk?”). These are scored on four point ordinal scales, $1=$ not at all, and $4=$ very much. The next 23 items are scored on the same ordinal scale, but ask specifically about the last week, e.g. "Have you had pain?" The final two questions are scored on a seven point ordinal scale, with 1 (very poor), and 7 (excellent) as anchors. The two items are global QOL questions, with one pertaining to health and the other one specifically to QOL. High values on all items in the questionnaire, except for the last two, indicate that the patient is experiencing high levels of that symptom. All the scales within the EO-QOL have satisfactory internal consistency as measured by Cronbach's alpha, with the exception of the role functioning $(\alpha=0.63)$ and cognitive functioning ( $\alpha=0.64)$ scales (Ringdal et al 1999).

\section{Participant Interviews}

Interviews were not part of the original methods. As such, with the interviews being done after the quantitative data the purpose of the interviews was to make up for the deficits in the quantitative data. As if covered later, due to the low number of individuals recruited and the high amount of attrition throughout the study made it difficult for relationships between the independent variable and dependant variables to be confidently described and realized.

Using semi-structured interview protocol (see Appendix F) the researcher conducted the interviews over the telephone, with each lasting 20 to 30 minutes. The interviews were centered around three areas: the individuals' physical activity patterns before, during, and after treatment; individuals' perceptions of their experiences during the intervention; and recommendations for future studies that aim to increase physical activity among cancer patients. The protocol was coloboralty created by the head researcher and three other individuals who were familiar with the subject area as well as the aims of the study. 


\section{Data Analyses}

When the study was originally developed recruitment was expected to be high enough to ensure able numbers of participants in both an experimental and control group. Due to many unseen complications the sample size needed to create statistical significance, $n=50$, was not reached. Instead, the research was able to recruit 10 individuals. Under the original study methods various between group quantitative statistical analyses were to be utilized (i.e. repeated measure ANOVA, independent $t$-tests). Due to the low recruitment, between-group comparisons were not completed. Instead, data was inspected visually by the researcher in a single-subject manner to identify trends and relationships.

To analyze the qualitative data, all interviews were recorded, then transcribed. Once the interviews and transcriptions were complete, the researcher and two additional colleagues each read over the interviews. Each individual read over the interviews to determine participants' answers to the questions as well as the overall theme of each interview. The researcher and the two aides then met to compare perceptions on each interview as well as the interviews as a group. As a result of these meetings, it was decided that a narrative approach best suited the data supplied from these interviews. Traditional qualitative analyses such as axial coding was not a good match to the data, instead, by using the interviews to "tell the stories" of these individuals as they went through their experience with the study and with cancer treatment best "fit" the data supplied. This analysis, though not as common as others, is a means by which researchers use to better understand events, behaviors, and cognitions (Polkinghorne, 1995).

\section{RESULTS}

A total of 10 individuals participated in the study, with starting dates ranging from February of 2009 to May of 2009. All participants provided pre-test data for both the CBI and 
the EO-QOL; though only half of the participants completed the same measures at the completion of their six-weeks within the study. In terms of providing step-counts and QOL measures weekly during their involvement in the study, four individuals provided complete data. On average, participants provided data for 3.7 of the six weeks.

All of the participants were female breast cancer patients. As per the inclusion criteria of the study, each participant was undergoing chemotherapy treatment for breast cancer for the first time. The youngest participant was 35 , the eldest 58 ; the average age was $49(\mathrm{SD}=7.42)$. Four of the participants had previously had surgery related to their diagnosis. The majority of the women $(n=6)$ were diagnosed between two and six months prior to the study, three of the women were diagnosed less than two months prior to their participation in the study, while one woman had been diagnosed over a year before she started the study.

Pre-test data

Self-efficacy for coping with cancer. At pre-test the mean total score on the CBI was $236.1(\mathrm{SD}=38.48)$. The average scores on the seven sub-scales can be found in Table 1 . Participants felt most efficacious in "Seeking and Understanding Medical Information" $(M=$ $8.16, \mathrm{SD}=1.14$ ) while they possessed the least amount of efficacy for "Coping with Treatment Related Side-effects" $(M=6.70, \mathrm{SD}=1.60)$.

Quality of life. At pre-test participants had low levels of nausea $(M=1.5, \mathrm{SD}=.53)$ and pain $(M=1.8, \mathrm{SD}=.98)$; though on average they were experiencing higher levels of fatigue $(M$ $=2.57, \mathrm{SD}=.74)$. Participants rated their overall health $(M=5, \mathrm{SD}=1.56)$ and $\mathrm{QOL}(M=5.10$, $\mathrm{SD}=1.66)$ towards the higher end of the seven-point scale. Scores across the five domains of functioning can be found in Table 2 .

Weekly data 
Step-counts. As referenced above, there was a fair amount of attrition throughout the study resulting in only four participants providing data across all six-weeks. There were 41 instances of participants providing weekly data during the duration of the study. The average amount of steps taken each week was 34,962.67 $(\mathrm{SD}=10,635.49)$. Table 3 provides a further break-down of the step-count progressions.

Global health and QOL. As is shown in Table 3, during the participants' time in the study, the average score on both the global health and QOL measures never rose above or was equal to the averages at the time of pre-test. The average score on both of these measures peaked in week one, and declined steadily throughout the six-weeks with the exception of week four which was the only increase during the six-weeks.

\section{Post-test data}

Self-Efficacy for coping with cancer. When compared directly to the pre-test scores of the whole group, the overall score fell while two of the sub-score averages rose ("Coping with treatment related side-effects" and "Accepting cancer/maintaining a positive attitude") while the rest fell below pre-test averages (Table 1). Though, when the scores are compared between pre and post for only those who filled out the post-test data, there are no significant differences in relation to the total score or any of the sub-scales.

Quality of life. As was with self-efficacy for coping with cancer, there were mixed results when the post-test scores on the EO-QOL were compared with the whole group's pre-test scores. However, when only the data from the individuals who provided post-test data was compared, there were no significant differences between pre and post-test with the exception of emotional functioning which fell, indicating that this area of patients of life was seen as better at the end of the study $t(4)=6.33, d=.61$ (Table 2$)$. 


\section{Individual Case Analyses}

Due to the low number of individuals who completed the full requirements for the study, comparisons across groups based on group placement or other variables are of little consequence. As such, the four individuals that did provide data across the eight data points were examined individually in a modified single-case design format.

Participant 2. Participant 2 was an employed, divorced and single 53 year-old women who had surgery before the study began. She was diagnosed less than six months prior to the study. On average she took 43,653 steps a day. Out of the four participants that have complete data, participant 2's weekly data most closely resembles the data that was hypothesized at the onset of the study as in her scores on her global health and QOL rose and fell with her stepcounts (Figure $1 \& 2$ ).

Upon visual inspection there were two large rises and one large fall in step-counts. From week one to two participant 2 increased her steps by over 1,000 (see Figure 1), then from week two to three fell over 2,000, and then was up another 1,000 from week three to four. These peaks and valleys corresponded with both health and QOL as both indices increased by one point from week one to two, then dropped at least two points from two to three and then gained again for week four.

When looking at Participant 2's pre and post-test data for self-efficacy for coping with cancer the post-test scores were lower across the board, with the largest gaps in "Maintenance of activity and independence" and "Seeking support". Also, her scores on the post-test were over 60 points lower than on the pre-test for total self-efficacy for coping with cancer. In regards to QOL, the results were mixed as some scores were higher (e.g. "Emotional functioning"), some lower 
(e.g. "Physical functioning"), and some the same (e.g. "Nausea") on the post-test than on the pretest.

Participant 6. Participant 6 was a married, employed, 53 year old woman who did not require surgery for her diagnosis at, or before, the time of her enrollment in the study. Participant 6 can be best described, in terms of this study, as steady.

Participant 6 averaged 23,062 steps per week and saw her steps increase from week one to week six (Figure 3). She indicated that both her QOL and health stayed steady throughoutsubmitting a score of four on both measures each week (Figure 4).

In terms of post and pre-test comparisons, on the CBI she increased by 17 points in regards to the total score and each sub-scale was also higher than pre-test levels. On the EOQOL her score on the "Role Functioning" rose indicating increased problems within that subscale. All the other sub-scales fell slightly pre to post with the exceptions of "Cognitive Functioning" and "Pain" which both stayed the same. These findings someone reflect the hypotheses as this participant increased PA throughout the study and saw her post-test scores on most measures of QOL and self-efficacy for coping cancer increase.

Participant 7. Participant 7 was a single, divorced, full-time homemaker who was diagnosed within six-months prior to participation. She had only undergone chemotherapy. Participant 7's steps were steady throughout the six weeks with the exception of week-three during which she dropped below 20,000 which was over 8,000 steps lower than her next lowest step-count total. However, participant 7's scores on both the QOL and Global Health measures do not follow the same trajectory throughout the six-weeks that the steps do (Figures $5 \& 6$ ). There is a steep drop from week two to three on both measures just as there was with the stepcounts, though that is the only similarity when the trends are investigated visually. 
Participant 7's scores on the CBI mostly dropped pre to post across the sub-scales; in addition her pre-test score of 166 on the CBI dropped to 145 at post-test. The exceptions to this trend were the subscale of "Accepting Cancer/Maintaining a Positive Attitude" which rose over two points; also on the CBI the sub-scale of "Seeking Support" stayed the same.

In regards to the EO-QOL only "Fatigue" and "Physical Functioning" rose, while all other scales dropped indicating an improvement on the given scale. The largest negative differences pre to post were on the "Pain" and "Role Functioning" subscales.

Participant 8. Participant 8 is married, employed fulltime, and was diagnosed less than two months prior to taking part in the study. She had only received chemotherapy in regards to her treatments for her breast cancer.

Participant 8 recorded some of the highest step-counts of the four participants that provided full step data. She recorded counts over 50,000 twice, which only one other participant matched. These two counts occurred during weeks four and five, though in week six her steps dropped down below 33,000. Participant 8's weekly scores in regards to QOL and Global Health followed a somewhat similar trend has the scores peaked during week four and tailed off towards week six (Figures $7 \& 8)$.

In regards to scores on the $\mathrm{CBI}$, participant 8 saw one subscale significantly drop pre to post, “Affective Regulation”, “Seeking and Understanding Medical Information” dropped slightly as well. The other subscales all rose, with the largest differences being on the "Stress Management for Medical Appoints" and "Coping with Treatment Related Side-Effects". Her total score also rose, from 230 to 257. 
On the EO-QOL, participant 8 was having more trouble with "Role Functioning" at the time of post-test compared to pre-test, her score on the "Pain" subscale was also slightly higher. All the other sub-scales either decreased or stayed the same between these two time points.

In summary, a review of individual cases partially supports the hypothesis that there are links between PA and psychosocial variables, self-efficacy and QOL in particular. A number of the cases displayed data in a manner that may show this link. In addition, when the four individuals' data are combined, the overall trend resembles one that would suggest these relationships: as participants' rose and fell in their step-counts their weekly scores in relation to health and QOL rose and drop as well.

\section{Qualitative Data}

All participants were contacted to gauge their interest in taking part in an interview about their experience in the study. Of the ten individuals who enrolled in the study, five responded. Interviews were set up with all five of these individuals and on four of these occasions telephone interview took place ranging from 12 to 25 minutes. One participant was too tired at the time of her scheduled interview and a subsequent interview was unable to be accomplished. Of the four interviewees, only one of the women interviewed also provided data across all data collection points. One provided weekly data for four of the six weeks as well as post-test data, one provided data for three of the six but no post-test data, and one provided data for one week and no posttest data. Due to the low rate of participation the development of themes and codes across interviews was difficult to achieve. Instead, each interview serves as a narrative. As such each interview will be discussed separately though some content will be discussed across the four interviews (e.g. suggestions for future studies).

Interview one: Participant 2. 
I guess I was at the point where it didn’t matter if I was wrong or not, there was no way I was going to spend the rest of my life walking like a 90 year-old woman. So if exercise was what I had to do then that's what I was going to do.

Participant 2 shared a very interesting relationship with PA during her interview. Participant 2 described herself as someone who did not value nor take part in PA before her diagnosis: "I hate exercising and I never exercised before..." However, her experience with breast cancer changed her views. She expressed that she "hated being wrong," meaning that she was wrong about the value of PA as she came to view it differently: "And when I felt so bad during and after chemo physical exercise is really what got me out of that whole experience, so it is what put me back on track. And I hate to be wrong."

Participant 2 saw PA as valuable because she felt that it helped her "reclaim" her body. Participant 2 experienced a regimen of radiation that left her weak and in pain. She wished that she had taken more time to be physically active before she began her treatment to build up her strength during that taxing time. She started to feel that she was reclaiming her body after her treatments when she was able to accomplish daily activities that she had been unable to accomplish during treatment:

So now it's just, it makes everything more normal and I don't have to depend on people to reach for things for me in cabinets, I can carry my own groceries, so you know it improves the level of enjoyment that I have - not that lifting groceries is all that enjoyable — but you know just to be able to do the things you want to do without it being a major family project is what I mean.

As a whole, participant 2's experience with and perception of PA activity changed greatly due to her experience with cancer. The current study may have aided in this mind-set change though the 
participant never specifically mentioned the study having a direct relationship in this way. Instead, this participant had the opportunity to do more structured PA in the form of physical therapy which she enjoyed and found to be useful on many levels. As was previously mentioned physical functioning was very important to this participant and physical therapy helped her regain her functioning after losing much of it due to treatment. Besides regaining functioning, this participant was also drawn to the structure that physical therapy provided: “...I liked physical therapy, to go in and have someone guide me, I was too tired to do it on my own." She made many positive references to working with a professional in this way and expressed that she felt accountable to make it in for physical therapy. Perhaps partly due to this participant's limited experience with PA having someone, to quote: "count the exercises and tell me switch...was extremely helpful" was needed to prove her "wrong" about PA and its benefits.

\section{Interview two: Participant 5.}

But the days that I was active and feeling good and was able to get out and go and walk and do whatever I just felt good, life was good, I was good, yeah I was just going through something at the time and that was it, just get through it and get back to normal life. Participant 5 was very active before diagnosis/treatment, stayed active during, and remained active after she completed her treatment. In fact, she taught her daughter to ride a bike while she was undergoing chemotherapy: "I even taught my daughter how to ride a bike when I was going through chemo...Everyone thought I was crazy".

Participant 5 found that her involvement in the study helped her stay motivated to be physically active; also, the inclusion of the pedometer helped her track her PA patterns: “...I got to see how much walking or how much activity I was doing during the time I would wear it, if it was low then it was like alright I got to pick it up..." Tracking her steps also allowed for 
participant 5 to use goal-setting. She would set a step-count goal and continually raise the numbers as she met her goals: “...I would set a goal for myself and if I did fifteen hundred then during the next day I would try to increase that..." As participant 5 now tries to regain her previous levels of activity she finds herself still using goal-setting as she's taking a methodical approach to working her physical capacities back up. She did not feel that any of the requirements of the study were difficult or a hindrance, though she did experience some sickness related to her chemotherapy that she felt kept her from being as active as she would have liked.

Activity is very important to participant 5 as she believes it "keeps her young" and makes her feel better: “...you feel better, mentally you feel better, you just feel better all together..." Besides staying young she felt that she needed to be active for her kids, "Staying active for them [my children]...it's just something that I have to do. I can't really explain it." Though her fight with cancer momentarily made participant 5 decrease her PA levels, she is now back to having activity being a critical part of who she is: "Going through that was like changing my whole routine my whole life now people can't even catch up with me."

Interview-three: Participant 4. "It was just a reminder of a time that was positive in my life. When I felt like I had control over my physical life." Participant 4, more than any other of the participants, reported that she had a very rough time with her cancer treatment. This may have been complicated further by other issues including a brain tumor and chronic fatigue syndrome. Due to all of these medical issues, participant 4 did not believe that she accomplished anything during her time in the study and she believed it was because of her problems with chemotherapy.

Though she did not feel that she accomplished much during her time in the study, she felt that it was a positive experience due to the fact that she was able to track her steps. Before 
getting sick, originally with a brain tumor then with cancer, participant 4 regularly wore a

pedometer and by wearing one once again she was able to reconnect with a time when she was in better health, and in her words: “...had control over my physical life.” She had put on weight during her treatment for cancer and she spoke to how she wished she could have been more active during that time period so that she would not have put on the weight. Though she wished that she had been more able to be active, participant 4 explained that during that time in her life "physical activity was not the most prevalent" thing on her mind. In addition to the sickness and the fatigue, she resides two hours from the cancer center and the constant trips back and forth wore her out.

Due to the many complications that this participant faced, she had trouble coming up with suggestions for ways to improve programs aimed at increasing PA during cancer treatment: “...it didn't work for me, but I think it could work for someone else.” She also sees activity as a tool to use against depression which can frequently occur during cancer treatment and wished she had been more active to combat her own feelings of depressing during this time. Overall, participant 4 was not, to her own admittance, a great candidate for an intervention such as the one used in the current study.

Interview four: Participant 10.

“...before I had cancer, and like I said I walked and I ran all my life, when I got cancer and heard the whole thing — walking will save your life and blah blah blah, I was like it's not true. And now I can see...walking saves a person life.”

Participant 10 reported that she was a very active individual before she was diagnosed with cancer, playing sports, running, etc. About one year prior to her original diagnosis she started feeling fatigued and was very inactive once she started chemotherapy. Prior to joining the study 
participant 10 had gone through a bi-lateral mastectomy and a previous round of chemotherapy. She viewed being a part of the study as a positive thing since it gave her the initiative to starting being active again, even if it was not to the same levels as before her diagnosis: "I guess it gave me the initiative to get up and continue to at least walk a good distance even though I don't run anymore."

Being active once again was an important thing for this participant. She felt that being active improved her overall quality of life: "Because if you're not active then your mind isn't motivated and [you] kind of slack on everything else." It was this motivation to be active that she viewed as the number one accomplishment she experienced during her time enrolled in the study; there were no additional things that she stated she had wished she had accomplished. This motivation was important to this participant because of her views on how PA relates to her overall feelings:

Well because when you're not active you tend to give up, once again mentally and physically, if there's no activity in your body then your body not only hurts but your mind begins to hurt mentally because it is part of giving up and not getting up every day or doing the things that you could be doing to make yourself better.

It is also of note, that this individual, who reported being one of the most active individuals interviewed as well as the youngest of all the participants in the study, was the only participant that specifically mentioned that walking is the preferred PA modality for this population. In addition, she believes that interventions such as the current one are best served to individuals during chemotherapy: "Chemo is one of the hardest times on a person and that's probably the only time during that time that they think of sitting down and I think that [physical activity] does a lot to motivate them. 
Summary. The four individuals who participated in interview were all different. Some were active long before their cancer diagnosis (participants five and ten), while one spoke to her previously apathetic views to PA (participant 2). One of the participants found that the intervention helped get her to be more active (participant 10), another was already trying to be active and found the study as another way to keep motivated (participant 5), one found value in PA not through the study but through physical therapy (participant 2), while one simply was too ill to be active though they wish they had been able to be (participant 4).

Though there were more different than similar, there were commonalities among the four transcripts. A few of the participants spoke to how PA helps individuals during cancer treatment "reclaim" their body or regain control over an area of their life. Motivation was a central theme of many of the interviews. This motivation seemed to go further than just trying to be more active. Participants spoke to how this motivation helped them other areas of their life, to keep fighting forward and to realize that they can get through the tough times they are facing.

None of the participants found the requirements of the study to be too taxing, and besides a few technical difficulties none reported problems with the study itself. With one exception (participant 4), walking did not seem to be too great of a task to ask of the participants. Though there were other activity types that participants mentioned they enjoyed or would recommend, such as water aerobics and functional exercises. Overall, it seems that the participants interviewed found the intervention to be beneficial and feasible.

\section{DISCUSSION}

This study aimed to investigate the effect of a walking intervention on three outcomes: PA levels, self-efficacy for coping with cancer, and QOL and though the study ended up being conducted in a manner that was far different than the one originally proposed, there were still 
numerous findings. The quantitative data collected seems to imply that the levels of PA achieved by participants did not positively impact most components of QOL or self-efficacy for coping with cancer as measured by the chosen instruments of the study. In fact, all of the physical domains assessed within these two constructs (e.g. "the maintenance of activity and independence" sub-scale of the CBI and the "physical functioning" of the EO-QOL) worsened pre to post. This is not a complete surprise as the levels of PA did not increase significantly over the course of the study and these constructs have been shown to decrease overtime for most cancer patients (Graves, 2003). The interviews backed this up as many of the participants talked about their physical struggles both with accomplishing PA and other physical daily functions such as putting away groceries. In addition, all four mentioned that they were not as active as they would have liked to have been, which could also be reflected quantitatively in the drop of the physical sub-scales.

Though the physical sub-scale scores dropped, the four sub-scales that did rise were all psychological (e.g. "accepting cancer" from the CBI and "emotional functioning from the EOQOL"; Tables 1 and 2). These findings echo many of the feelings of the participants interviewed. Three of the interviewees mentioned that though they were not being as active as they would have liked, the positive effects of PA were still very worthwhile.

A closer look at the quantitative data showed that some of the hypotheses may have been supported. Among the four individuals who completed all the weekly data points, upon visual comparison of the weekly step-count and weekly QOL and global health measures, two individuals' data patterns seem to support the hypothesis that there is positive relationship between PA and QOL; while only one participant's data disputes this hypothesis (her QOL and global health data stayed the same throughout while step-counts fluctuated). 
The qualitative data collected added depth to the findings. The interviewees expressed that PA was not only important, but with the exception of one interviewee, they expressed that the means of the intervention, that is walking, was tolerable. These views have been reflected many times in the literature (e.g. Conn, et al, 2006; Losito et al, 2006; Schmitz et al, 2005; Stevinson, Lawlor, \& Fox, 2004). Though all interviewees reported, as most patients have (Courneya \& Friedenreich, 1997 a \& b), that their PA levels dropped during treatment, they all expressed a desire to continue to be, or even in one case, start to be, active.

Activity was important to these individuals for a number of reasons. Chief among these was an idea that PA kept them motivated to get better. Three interviewees spoke to how cancer treatment can be a time when individuals feel depressed, feel like things are outside of their control, and feel like they cannot accomplish the things they used to be able to. Physical activity, in their minds, helps to raise motivation during this time-motivation to be active, to gain control of their lives and to increase their well-being, both physical and mentally. Previous studies back up many of these insights from the interviewees. Researchers have postulated that promoting PA during cancer treatment might be an effective tool for individuals who feel that they have lost control (Demark-Wahnefried et al, 2003). In addition, some of the interviewees spoke to the ability of exercise to decrease depression, which is both seen in the general PA literature (Lox et al, 2006) and within the disease literature (Johnson et al, 2003).

Self-efficacy for coping with cancer was chosen as a key outcome variable due for many reasons. Self-efficacy to be active is believed to help raise individuals' self-concept, selfconfidence, and perhaps their self-efficacy in other areas of their life (Leith, 2002). In addition, self-efficacy has been shown to positively relate to QOL (Cunningham, Lockwood, \& Cunningham, 1991; Lev \& Owen, 2001), which drops significantly during cancer treatment 
(Gall, et al, 2007; Valenti et al, 2008). Though none of the interviewees mentioned self-efficacy in direct terms, and though it may be an invalid extrapolation on the researcher's part, the interviewees insights about PA helping them "reclaim" their body, regain "control", and "stay motivated", may show that a relationship between increased PA and mental well-being (e.g. selfefficacy) exists.

These themes of control and motivation that arose from the interviews might be explained through the lens of self-determination theory (SDT). Very briefly SDT seeks to understand motivation, specifically how motivation relates to individuals basic psychological needs of competence, autonomy, and relatedness (Ryan \& Deci, 2000). When these needs are satisfied they lead individuals to possess enhanced self-motivation and mental well-being. It could be postulated that the motivation that many of the interview participants spoke of arose from their fulfillment of some of these needs. The cancer process is often a time when one loses a great bit of their health autonomy: that is their belief that they are in control of their own health. As many of the participants mentioned, they felt that by increasing their PA they were gaining back "control", or "reclaiming" their body or, to put it another way, gaining back autonomy. Theoretically, by gaining back this sense of autonomy they were shifting their control of their health back from an outside source (cancer) to an internal one (themselves). One of the main tenants of SDT, is that as individuals' perceived location of control, or as the authors define it: "locus of causality" (Ryan and Deci, p. 72), moves from external to internal, their motivation shifts from extrinsic to intrinsic. And while motivation is useful in any form, intrinsic motivation is believed to be the most beneficial in terms of continued fulfillment of behaviors. In this sample that behavior may have been more psychological than physical: continuing to believe that they could positively deal with their illness. Though more thorough work is needed to explore 
the relationships between PA and well-being through the framework of SDT, it does seem that that SDT is one potential concept that may help to better understand the phenomena that occur when PA is introduced during cancer treatment.

\section{Limitations}

Many limitations are present in this study. First and foremost among the limitations is the small sample size. The final sample size is only $20 \%$ of the desired sample sought. Besides a small sample size, the low rate at which participants provided data made it difficult for meaningful comparisons to be made. There could be many variables that attributed to these issues. Regardless, both of these problems point to issues with the study's proposed methods. The current study's reliance on participants to provide data on their own and the low amount of face-to-face contact between the researcher and the participants are probably two of the main factors that attributed to the low amount of data collection. The study's inclusion criteria may have put the researcher at a disadvantage as many potential participants were not eligible due to their cancer being a reoccurrence.

Another limitation of the current study was the amount of time that elapsed between individuals' participation within the study and the interviews conducted to investigate their perceptions their experience. This gap in time may have prevented individuals from providing accurate recollections of their experiences as they were reflecting back a number of months.

\section{Suggestions for Future Studies}

Though the numerous limitations of the study led to minimal results in the classical sense (e.g. significant statistical findings and robust coding of qualitative data), the challenges faced provided the researcher numerous opportunities to formulate potential changes to the study to better address the subject area at hand. First and foremost there were flaws with the recruitment 
procedures utilized. Many past studies have relied on health professionals to recruit participants. Within the current study, though it was through the aid of an oncologist, nurse practitioner, and physician's assistant that potential participants were identified, it was only when the researcher was present at the cancer center that patients were contacted about potential recruitment. A very low number of individuals declined participation which may suggest that with more contact with patients sample size may have approached the desired $n$. As such, in future studies, researchers would be best served to either A) be more enmeshed within the facilities from which they are recruiting or B) have someone who has more regular contact with patients (read potential participants) do the initial recruitment. The current study was front loaded in terms of data collection; when participants were recruited they provided all pre-test data. This led to a cumbersome recruitment procedure that would have been bothersome to the cancer center's staff. It may have been more reasonable, and future studies may find it better, to utilize a more streamlined recruitment procedure. Instead of needing the 20 minutes to collect consent and data, simply collecting consent may reduce the time needed to a few minutes; after this time the researcher could then contact the participants for the rest of the data. This would be more amenable to the schedules and workloads of the health professionals that have the most contact with the participants.

Besides recruitment, the other area that would have been drastically improved upon was data collection. Not only was there a high rate of attrition the reporting of data was done by participants which increased the possibility that data was incorrectly reported. Though measures were taken to objectify the PA data collected (i.e. the use of pedometers), the self-reporting of the data and the myriad of potential technical issues with pedometers could have errors in the reporting of PA data. Advances in technology could address these issues. Accelerometers could 
be utilized which are a more objective and richer source of PA data, in addition, these devices can now be set to send data to a central source each time they are connected to a computer thus taking the reporting of data out of the hands of participants. This could also help with attrition as the demands of participants would be lessened.

Lastly, though the inclusion of qualitative interviews was added to the methods due to the low amount of quantitative data collected, the interviews proved to be a very valuable source of information. As such, the inclusion of qualitative procedures is a potential avenue for future studies to employ. In this case, the interviews were done after the completion of recruitment and after all participants had taken part in the intervention. This form of interview is very valuable (though ideally they would happen closer to the time when participants end) and should be replicated. In addition, it would be advantageous to incorporate interviews throughout the duration of the study. The potential benefits would be two-fold: they would provide more data and would help to enrich any quantitative data; and they could help with attrition as they would keep the participants engaged in the study. The limited amount of contact between the researcher and the participants in the current study may have hurt data collection and an increase in contact may help to remind participants to provide data and follow the intervention.

\section{Summary and Future Directions}

The effect of PA during cancer treatment is fast becoming a robust area of study, but there are many avenues of exploration that warrant additional attention. A better understanding of how PA affects mental well-being represents one such area of investigation. The limited qualitative findings of the current study suggest that some patients may believe a relationship exists between PA and mental well-being, though larger studies are needed to help validate this finding. Besides qualitatively investigating PA and its effect on mental well-being, more 
quantitative studies are needed. Previous researchers have called for more studies utilizing a control/experimental two-group design. The current study failed to address this weakness. Though recent studies have utilized two-group designs (i.e. Cadmus et al, 2009) this need is still very present. In addition, more regimented reporting of exercise interventions needs to be reported. One of the more prevalent struggles in this area of literature is the lack of knowledge about the best modality of PA. Studies have been done with aerobic and anaerobic; intense and light; home-based and supervised exercise. However, many studies lack quantitative data on PA actually completed by the participants. The current study aimed to address this limitation via the use of pedometers to assess rates of PA. Pedometers or accelerometers are two such ways to better track, and then report, PA rates. By better tracking rates relations between PA and psychosocial variables may be better understood then the current method of comparing base-line and post-test data of individuals who go through an exercise program.

The current study, though limited in its scale and therefore in its ability to concretely externalize its findings, showed that there might be relations between PA and self-efficacy for coping with cancer. At the very least this study begins to show that cancer patients do realize that PA has wide reaching effects on their well-being during treatment. Future studies need to build on this. Though the research foundation is growing, there is still much left to better understand in the hopes of promoting overall well-being with this population. 


\section{REFERENCES}

Aaronson N.K, Ahmedzai S, Bergman B, Bullinger M, Cull A, Duez N.J, et al. (1993) The European organization for research and treatment of cancer QLQ-C30: A quality-of-life instrument for use in international clinical trials in oncology. Journal of the National Cancer Institute 85, 365-376.

Ahmedin, J., Siegel, R., Ward, E., Hao, Y., Xu, J., \& Thun, M.J. (2009). Cancer statistics, 2009. CA: A Cancer Journal for Clinicians, 59, 225-249.

Ahmedin, J., Siegel, R., Ward, E., Hao, Y., Xu, J., Murray, T., et al. (2008) Cancer statistics, 2008. CA: A Cancer Journal for Clinicians, 58, 71-963.

American Cancer Society (2009).

American Cancer Society (2007). Cancer facts and figures 2006. American Cancer Society. Retrieved February 7 2007, from http://www.cancer.org/downloads/STT/CAFF2007PWSecured.pdf.

Bandura, A., (1986). Social foundation of thought and actions: A social cognitive theory. Englewood Cliffs, NJ: Prentice Hall.

Berry, D., Savoye, M., Melkus, G., \& Grey, M. (2007). An intervention for multiethnic obese parents and overweight children. Applied Nursing Research, 20, 63-71.

Cadmus, L.A., Salovey, P., Yu, H., Chung, G., Kasi, S., \& Irwin, M.L. (2009). Exercise and quality of life during and after treatment for breast cancer: Results of two randomized controlled trials. Psycho-Oncology, 18, 343-352.

Conn, V.S., Hafdahl, A.R., Porock, D.C., McDaniel, R., \& Nielsen, P.J. (2006). A meta-analysis of exercise interventions among people treated for cancer. Support Care Cancer 14, 699712. 
Courneya, K.S. (2003). Exercise in cancer survivors: An overview of research. Medicine \& Science in Sports and Exercise, 35, 1846-1852.

Courneya, K.S. \& Friedenreich, C.M. (1997a). Relationship between exercise during treatment and current quality of life among survivors of breast cancer. Psychosocial Oncology, 15, $35-37$.

Courneya, K.S. \& Friedenreich, C.M. (1997b). Relationship between exercise pattern across the cancer experience and current quality of life in colorectal cancer survivors. Alternative Complementary Medicine, 3, 215-226.

Cunningham, A.J., Lockwood, G.A., \& Cunningham, J.A. (1991). A relationship between perceived self-efficacy and quality of life in cancer patients. Patient Education and Counseling, 71, 71-78.

Daly, J., Sindone, A.P., Thompson, D.R., Hancock, K., Chang, E. \& Davidson, P. (2002). Barriers to participation in and adherence to cardiac rehabilitation programs: A critical literatre review. Procress in Cardiovasvular Nursing, 17, 8-17.

De Boer, M.F., Van den Borne, B.V., Pruyn, J.F.A., Ryckman, R.M., Volovics, L., Knegt, P.P, et al. (1998). Psychosocial and physical correlates of survival and recurrence in patients with head and neck carcinoma: Results of a 6-year longitudinal study. Cancer, 83, 25672579.

Demark-Wahnefried, W., Morey, M.C., Clipp, E.C., Pieper, C.F., Clutter Snyder, D., Sloane, R., \& Cohen, H.J. (2003). Leading the way in exercise and diet (project LEAD): Intervening to improve function among older breast and prostate cancer survivors. Control Clinical Trials, 24(2), 206-223. 
Demark-Wahnefried, W., Peterson, B., McBride, C., Lipkus, I., \& Clipp, E. (2000). Current health behaviors and readiness to pursue life-style changes among men and women diagnosed with early stage prostate and breast carcinomas. Cancer, 88(3), 674-684.

Dugard, P. \& Todman, J. (1995). Analysis of pre-test post-test control group designs in educational research. Educational Psychology, 15, 181-199.

Foulger, D. (2004). Statistical Methods MediaSpaceWiki. Retrieved on 4-25-08 from http://evolutionarymedia.com/wiki.htm?StatisticalMethods.

Graves, K.D. (2003). Social cognitive theory and cancer patients' quality of life: A meta-analysis of psychosocial intervention components. Health Psychology, 22, 210-219.

Herreo, G., San Juan, A.F., Fleck, S.J., Balmer, J., Perez, M, Canete, S. et al. (2006). Combined aerobic and resistance training in breat cancer survivors: A randomized controlled pilot trial. Internal Journal of Sports Medicine, 27, 573-580.

Holmes, M. D., Chen, W. Y., Feskanich, D., Kroenke, C. H., \& Colditz, G. A. (2005). Physical activity and survival after breast cancer diagnoses. Journal of the American Medical Association, 293, 2479-2486.

Johnson, M.O., Catz, S.L., Remien, R.H., Rotheram-Borus, M.J., Morin, S.F., Charlebois, E., et al. (2003). Theory guided, empirically supported avenues for intervention on HIV medication nonadherence: Findings from the health living project. AIDS Patient Care and STDs, 17, 645-656.

Johnson, M.O., Gamarel, K.E., \& Dawson Rose, C. (2006). Changing HIV treatment expectancies: A pilot study. AIDS Care, 18(6), 550-553. 
Jordhoy, M.S., Ringdal, G.I., Helbostad, J.L., Oldervoll, L., Loge, J.H., \& Kaasa, S. (2007). Assessing physical functioning: A systematic review of quality of life measures developed for use in palliative care. Palliative Medicine, 21, 673-682.

Kara, N., van der Bijl, J.J., Shortridge-Baggett, L.M., Asti, T., \& Erguney, S. (2006) Crosscultural adaptation of the diabetes management self-efficacy scale for patients with type 2 diabetes mellitus: Scale development. International Journal of Nursing Studies, 43, 611621.

Knols, R., Aaronson, N.K., Uebelhart, D., Fransen, J., \& Aufdemkampe, G. (2005). Physical exercise in cancer patients during and after medical treatment: A systematic review of randomized and controlled clinical trials. Journal of Clinical Oncology, 23, (16), 38303842.

Kreitler, S., Peleg, D. \& Ehrenfeld, M. (2007). Stress, self-efficacy and quality of life in cancer patients. Psycho-Oncology, 16, 329-341.

Leith, L.M. (2002). Foundations of exercise and mental health. Morgantown, WV: Fitness Information Technology.

Lev, E.L. \& Owen, S.V. (2001). Counseling women with breast cancer using principles developed by Albert Bandura. Perspective Psychiatry Care, 37, 107-08.Patient Education and Counseling, 17, 71-78.

Losito, J.M., Murphy, S.O., Thomas, M.L. (2006). The effects of group exercise on fatigue and quality of life during cancer treatment. Oncology Nursing Forum, 33 (4), 821-825.

Lox, C., Martin Gines, K. A., \& Petruzzello, S.J. (2006). The Psychology of Exercise Integrating Theory and Practice. Scottsdale, AZ: Holcomb Hathaway. 
McBride, C.M., Clipp, E., Peterson, B.L., Lipkus, I.M., \& Demark-Wahnefried, W. (2000). Psychological impact of diagnosis and risk reduction among cancer survivors. PsychoOncology, 9, 418-427.

McNeely, M.L., Campbell, K.L., Rowe, B.H., Klassen, T.P., Mackey, J.R., \& Courneya, K.S. (2006). Effects of exercise on breast cancer patients and survivors: a systematic review and meta-analysis. Canadian Medical Association Journal, 175(1), 34-41.

Meadows, A.T., Varricchio, C., Crosson, K., Harlan, L., McCormick, P., Nealon, E., et al. (1998). Research issues in cancer survivorship: Report of a workshop sponsored by the office of cancer survivorship, national cancer institute. Cancer Epidemiology, Biomarkers \& Prevention, 7, 1145-1151.

Merluzzi, T.V., \& Martinez Sanchez, M.A., (1997b). Perceptions of coping behaviors by persons with cancer and health care providers. Psycho-Oncology, 6, 197-203.

Merluzzi, T.V., Nairn, R.C., Hedge, K., Martinez Sanchez, M.A., \& Dunn, L. (2001). Selfefficacy for coping with cancer: Revision of the cancer behavior inventory (Version 2.0). Psycho-Oncology, 10, 206-217.

Merluzzi, T.V., Nairn, R.C., \& Martinez Sanchez, M.A. (1999). The Cancer Behavior Inventory Manual.

Mock, V., Atkinson, A., Barsevick, A., Cella, D., Cimprich, B., Cleeland, C. et al. (2003). NCCN practice guidelines for cancer-related fatigue. Oncology, 14, 151-161.

Mock, V., Frangakis, C., Davidson, N.E., Ropka, M.E., Pickett, M., Poniatowski, B. et al. (2005) Exercise manages fatigue during breast cancer treatment: A randomized controlled trial. Psycho-Oncology, 14, 464-477. 
Mock, V., Pickett, M., Ropka, M.E., Muscari Lin, E., Stewart, K.J., Rhodes, V.A. et al. (2001). Fatigue and quality of life outcomes of exercise during cancer treatment. Cancer Practice, 9, 119-127.

Mustian, K.M., Griggs, J.J., Morrow, G.R., McTiernan, A., Roscoe, J.A., Bole, C.W., Atkins, J.N., \& Issel, B.F. (2006). Exercise and side effects among 749 patients during and after treatment for cancer: a University of Rochester cancer center community clinical oncology program study. Support Care Cancer, 14, 732-741.

Na, Y., Kim, M., Kim, Y., Ha, Y., \& Yoon, D.S. (2000). Exercise therapy effect on natural killer cell cytotoxic activity in stomach cancer patients after curative surgery. Archives of Physical Medicine Rehabilitation, 81, 777-779.

National Cancer Institute. (1999). Chemotherapy and you: A guide to self-help during cancer treatment. Retrieved March 14, 2007 from http://www.cancer.gov/cancertopics/chemotherapy-and-you/page2

Nieman, D.C., Cook, V.D., Henson, D.A., Suttles, J., Rejeski, W.J., Ribisl, P.M. et al. (1995). Moderate exercise training and natural killer cell cytotoxic activity in breast cancer patients. International Journal of Sports Medicine, 16, 334-337.

Norris, S.L., Engelgau, M.N., \& Narayan, K.M. (2001). Effectiveness of self-management training in type 2 diabetes: Systematic review of randomized controlled trials. Diabetes Care, 21, 561-587.

Perna, F.M., Craft, L., Carver, C.S., \& Antoni, M.H. (2008). Negative affect and barriers to exercise among early stage breast cancer patients. Health Psychology, 27, 275-279. Polkinghorne, D.E. (1995). Narrative configuration in qualitative analysis. International Journal of Qualitative Studies in Education, 1, 5 - 23. 
Ringdal, K., Ringdal, S., Kaasa, K., Bjordal, F., Wisloff, S., Sundstrom, \& Hjermstad, M.J. (1999). Assessing the consistency of psychometric properties of the HRQol scales within the EO-QOL across populations by means of the Mokken Scaling Model. Quality of Life Research, 8, 25-43.

Rowland, J.H., Aziz, N., Tesauro, G., \& Feuer, E.J. (2001). The changing face of cancer survivorship. Seminars in Oncology Nursing, 17(4), 236-240.

Ryan, R.M. \& Deci, E.L. (2000). Self-determination theory and the facilitation of intrinsic motivation, social development, and well-being. American Psychologist, 55, 68-78.

Schmitz, K.H., Holtzman, J., Courneya, K.S., Masse, L.C., Duval, S., Kane, R. (2005). Controlled physical activity trials in cancer survivors: A systematic review and metaanalysis. Cancer Epidermal Biomarkers \& Prevention 14 (7), 1588-1595.

Stevinson, C., \& Fox, K.R. (2006). Feasibility of an exercise rehabilitation programme for cancer patients. European Journal of Cancer Care, 15, 386-396.

Stevinson, C., Lawlor, D.A., \& Fox, K.R. (2004). Exercise interventions for cancer patients: Systematic review of controlled trials. Cancer Causes and Control 15, 1035-1056.

Tennstedt, S.L. (2000). Empowering older patients to communicate more effectively in the medical encounter. Clinics in Geriatric Medicine, 16, 61-70.

Valenti, M., Giampiero, P., Aielli, F., Verna, L., Cannita, K., Manno, et al (2008). Physical exercise and quality of life in breast cancer survivors. International Journal of Medical Science, 5, 24-28.

Vallance, J.K.H., Courneya, K.S., Plotnikoff, R.C, \& Mackey, J.R. (2008). Analyzing theoretical mechanisms of physical activity behavior change in breast cancer survivors: Results from the activity promotion (ACTION) trial. Annals of Behavioral Medicine, 35, 150-1583. 
van Weert, E., Hoekstra-Weebers, J.E.H.M., May, A.M., Korstjens, I., Ros, W.J.G., \& van der Schans, C.P. (2008). The development of an evidence-based physical self-management rehabilitation programme for cancer survivors. Patient Education and Counseling, 71, 169-190.

Zizzi, S., Vitullo, E., Rye, J., O'Hara-Tompkins, N., Abildso, C., Fisher, B., et al. (2006, January). Impact of a three-week pedometer intervention on high school students' daily step counts and perceptions of physical activity. American Journal of Health Education, 37(1), 35-40. 


\begin{tabular}{|c|c|c|c|}
\hline Factor & $\begin{array}{l}\text { Pre-test } \\
\mathrm{M}(\mathrm{SD}) n=10\end{array}$ & $\begin{array}{l}\text { Post Test } \\
\mathrm{M}(\mathrm{SD}) n=5\end{array}$ & $\begin{array}{l}\text { Effect-size } \\
d\end{array}$ \\
\hline Maintenance of Activity and & $7.66(1.29)$ & $6.68(2.42)$ & 0.51 \\
\hline \multicolumn{4}{|l|}{ Independence } \\
\hline Seeking and Understanding Medical & $8.16(1.14)$ & $7.72(1.76)$ & 0.30 \\
\hline \multicolumn{4}{|l|}{ Information } \\
\hline Stress Management for Medical & $7.36(1.44)$ & $7.04(2.8)$ & 0.14 \\
\hline \multicolumn{4}{|l|}{ Appointments } \\
\hline Coping with Treatment Related Side & $6.70(1.60)$ & $7.36(2.16)$ & 0.35 \\
\hline \multicolumn{4}{|l|}{ Effects } \\
\hline Accepting Cancer/Maintaining a Positive & $7.56(1.53)$ & $8.04(1.15)$ & 0.35 \\
\hline \multicolumn{4}{|l|}{ Attitude } \\
\hline Affective Regulation & $6.74(1.46)$ & $6.16(1.61)$ & 0.38 \\
\hline Seeking Support & $7.33(1.66)$ & $7.2(1.66)$ & 0.08 \\
\hline Total & $236.1(38.48)$ & $228.4(52.96)$ & 0.17 \\
\hline
\end{tabular}


Table 2. EO-QOL Functioning Scores

\begin{tabular}{llll}
\hline Area of Functioning & Pre-test & Post-test & Effect-size \\
& $\mathrm{M}(\mathrm{SD}) n=10$ & $\mathrm{M}(\mathrm{SD}) n=5$ & $d$ \\
\hline Physical & $1.56(0.50)$ & $1.80(0.69)$ & 0.40 \\
Role & $2.05(1.09)$ & $2.47(0.64)$ & 0.47 \\
Cognitive & $2.35(1.27)$ & $2.10(1.34)$ & 0.18 \\
Emotional & $2.25(1.03)$ & $1.65(0.79)$ & 0.65 \\
Social & $2.45(0.86)$ & $2.70(1.40)$ & 0.22 \\
\hline
\end{tabular}


Table 3. Weekly step counts, QOL, and global health scores

\begin{tabular}{llll}
\hline & \multicolumn{1}{l}{ Steps } & QOL & Health \\
Week $(n)$ & M (SD) & M (SD) & M (SD) \\
\hline $1(9)$ & $31121(11968)$ & $4.80(1.23)$ & $4.60(1.17)$ \\
$2(7)$ & $33896(10907)$ & $4.14(0.69)$ & $4.14(0.69)$ \\
$3(7)$ & $29889(13078)$ & $3.29(1.60)$ & $3.29(1.38)$ \\
$4(6)$ & $42009(19677)$ & $4.00(1.67)$ & $4.17(1.47)$ \\
$5(4)$ & $36946(13145)$ & $3.25(1.50)$ & $3.25(1.50)$ \\
$6(4)$ & $33243(4771)$ & $3.00(0.82)$ & $3.00(8.16)$ \\
\hline
\end{tabular}


Figure 1: Participant 2's steps

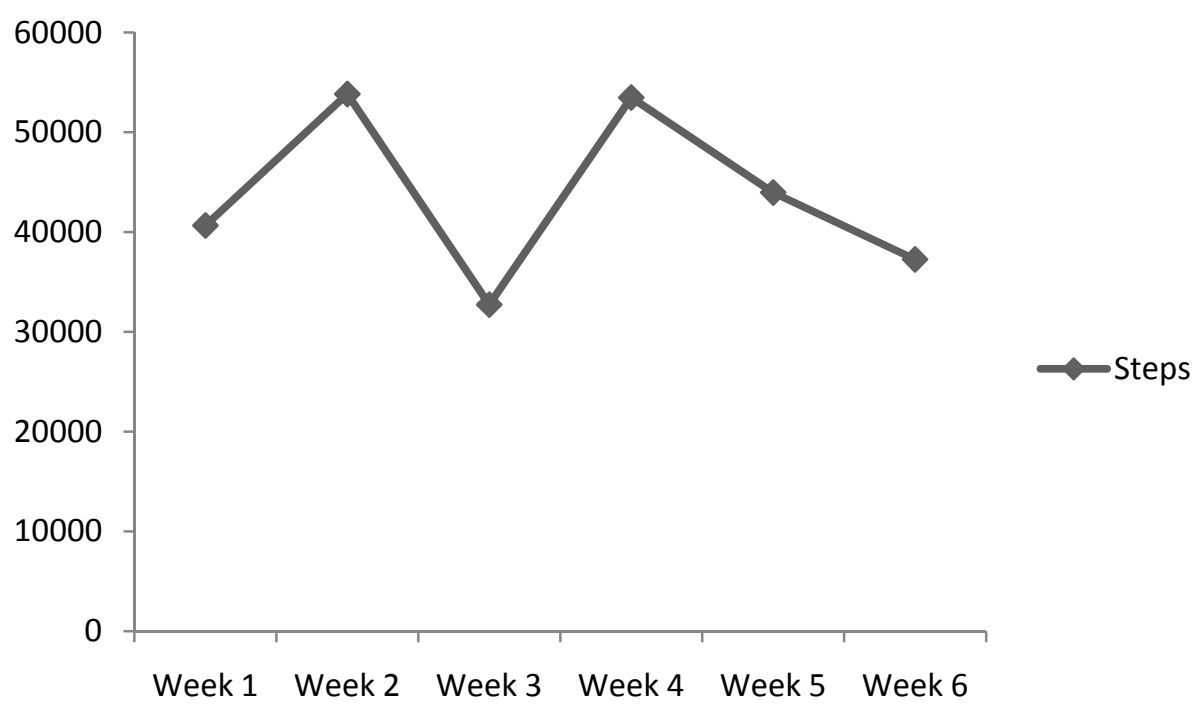

Figure 2: Participant 2's QOL and global health

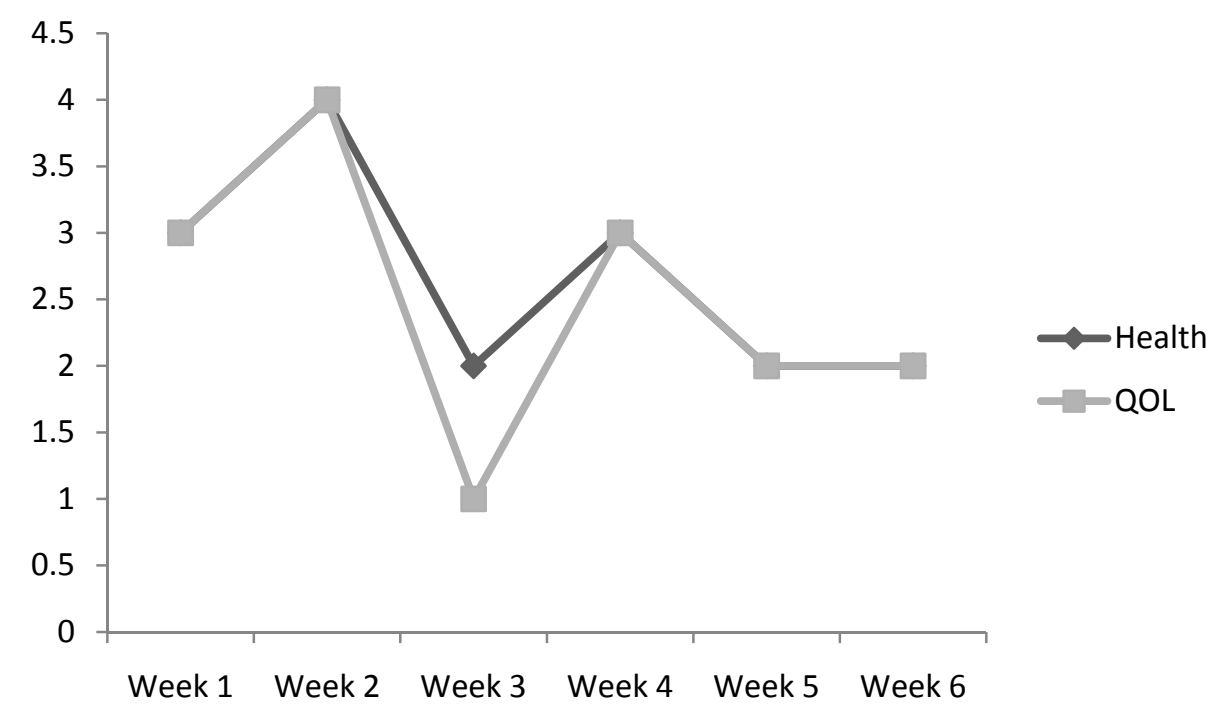


Figure 3: Participant 6's steps

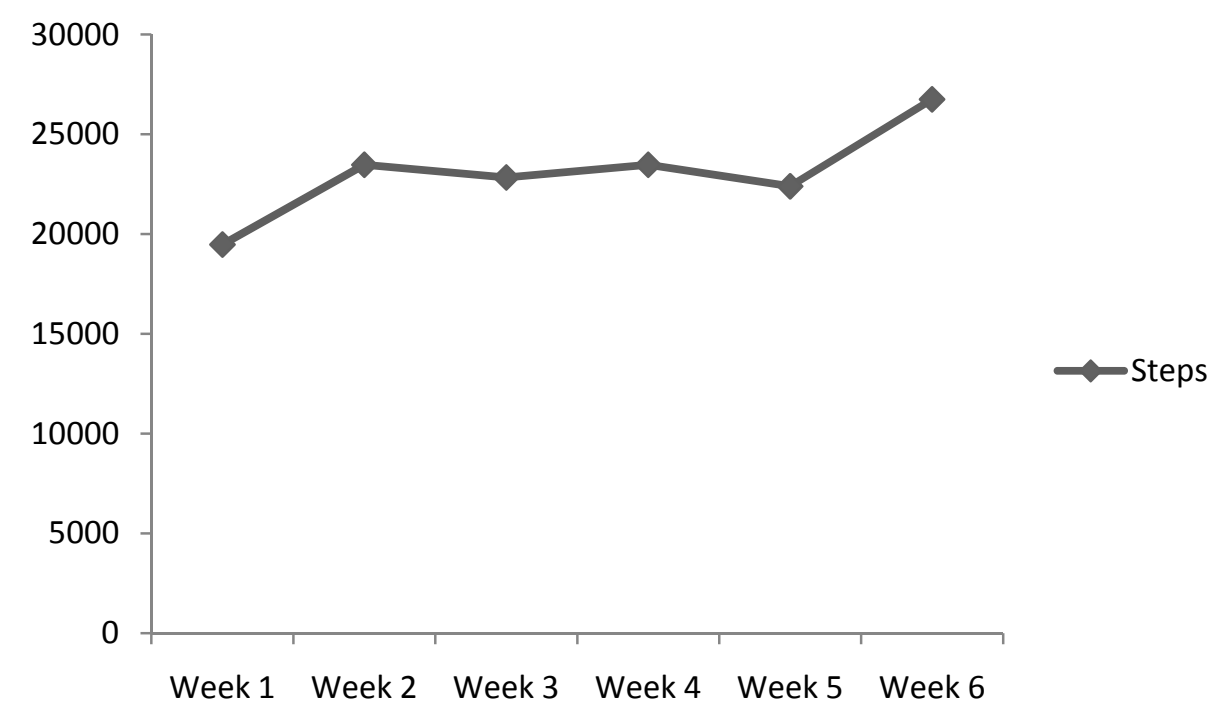

Figure 4: Participant 6's QOL and global health

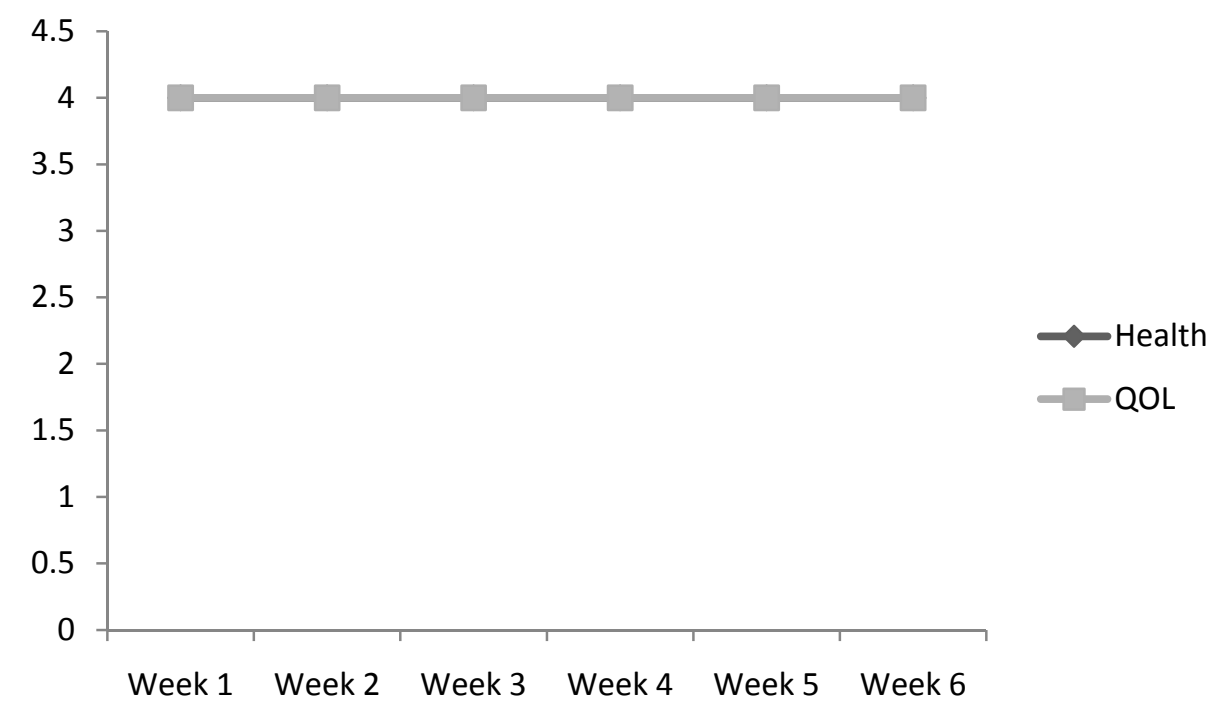


Figure 5: Participant 7's steps

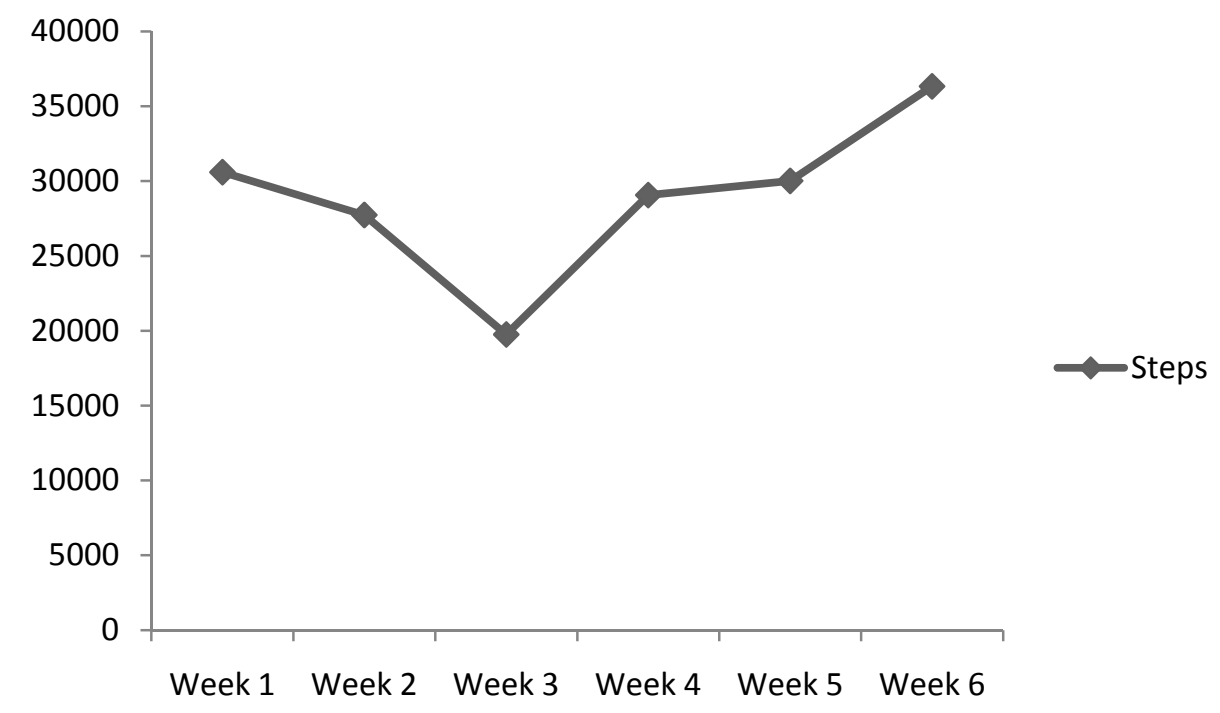

Figure 6: Participant 7's QOL and global health

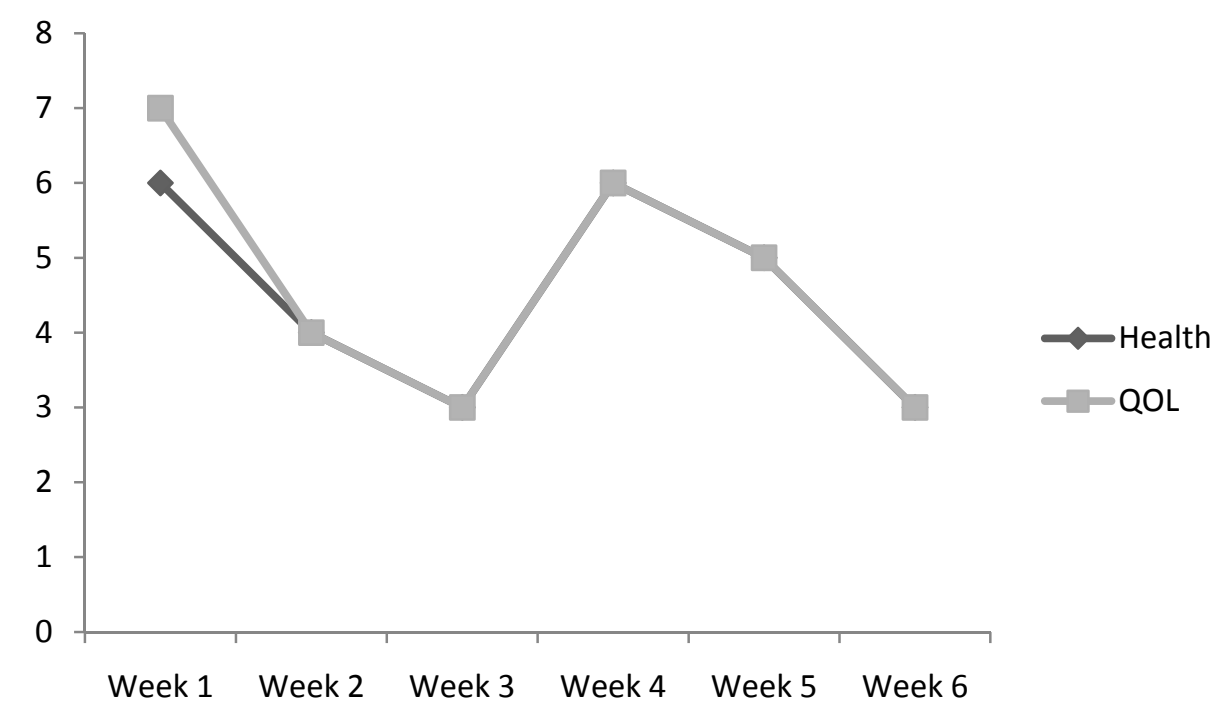


Figure 7: Participant 8's steps

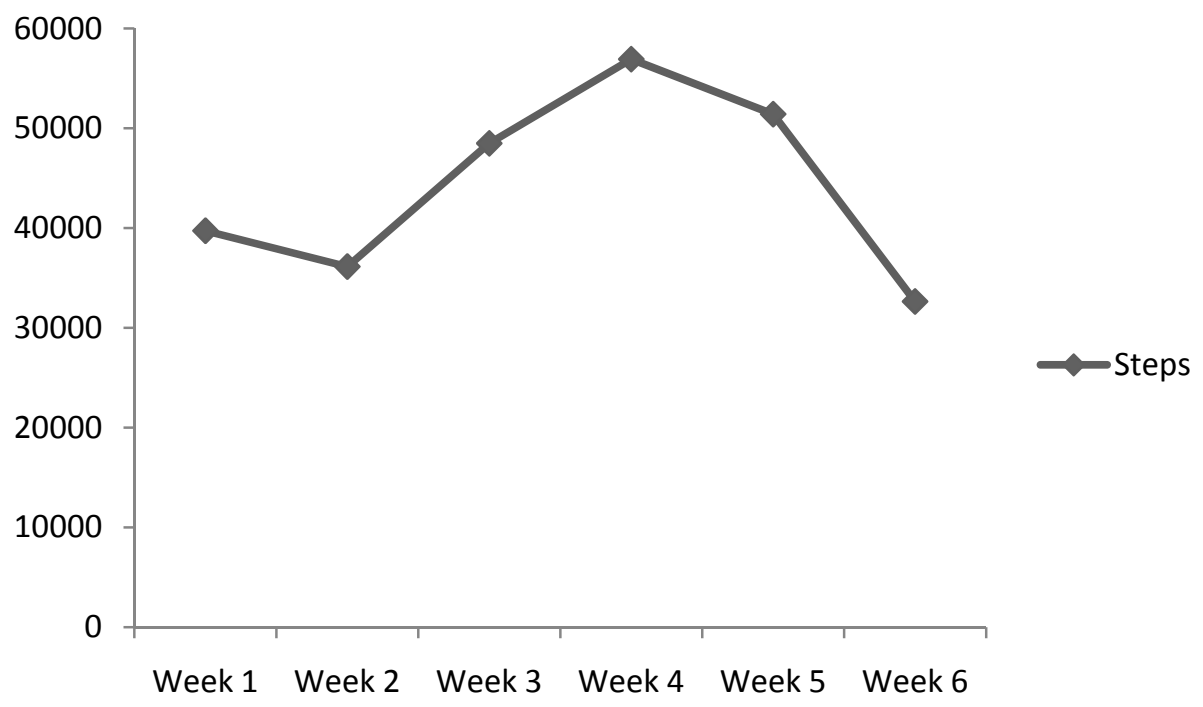

Figure 8: Participant 8's QOL and global health

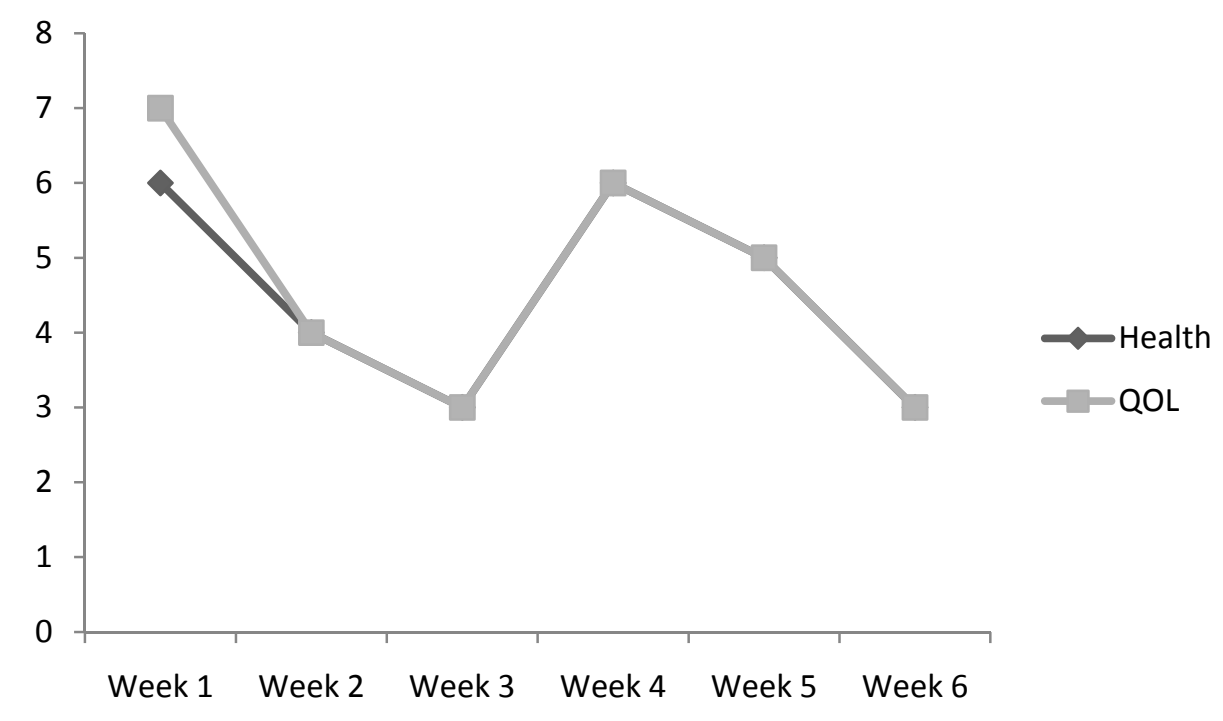


Figure 9: Combined participants' steps

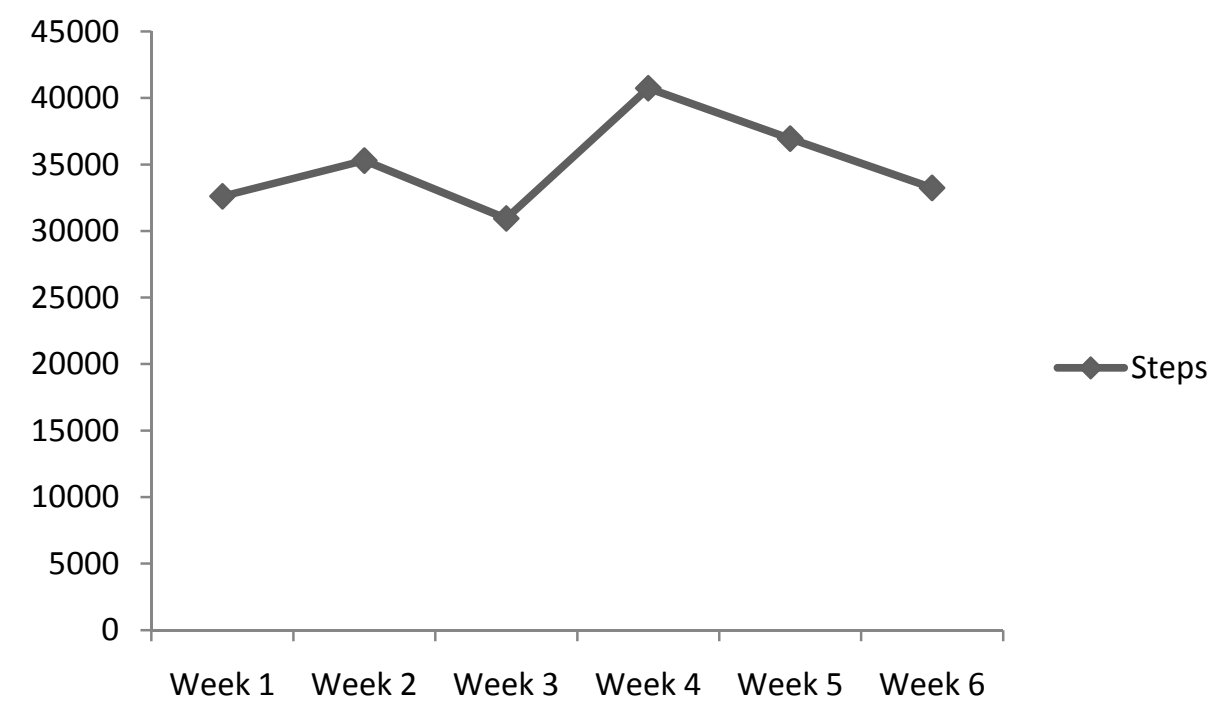

Figure 10: Combined participants' QOL and global health

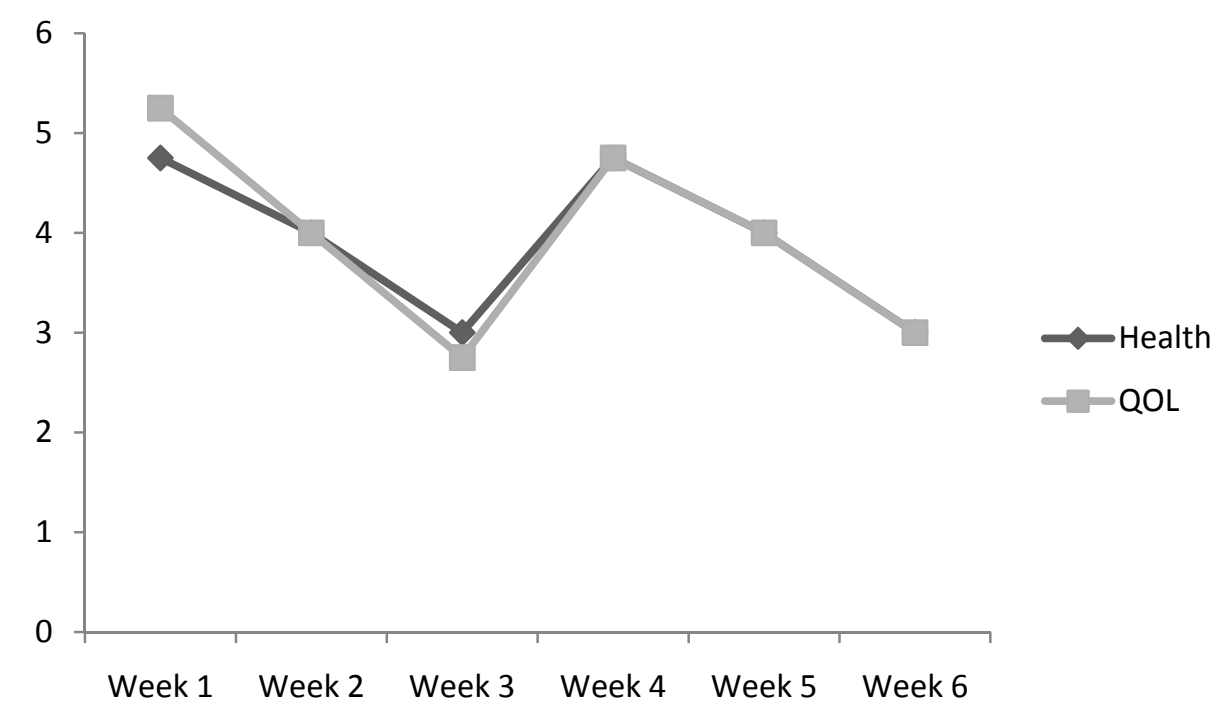




\section{Appendix A: Review of Literature \\ Introduction}

Over one and half million individuals across the United States will be diagnosed with cancer this year alone (Ahmedin et al, 2008). When this number is added to the 10 and half million cancer survivors who have already fought this disease, it becomes very apparent that cancer affects many lives (American Cancer Society, 2007). Cancer is this country's second leading cause of death, accounting for just over a fifth of all deaths (Admedin et al, 2008). Do to these alarmingly high numbers, there have been billions upon billions of dollars spent on cancer research. Much of this research money has gone into cancer prevention, detection, and treatment, and rightfully so (Bren, 2007). Though no cure has been found, great strides have been made; and with each passing year individuals who are diagnosed with cancer have higher survival rates. As these survival rates climb, there has been a push towards making the cancer treatment process a more manageable ordeal for patients.

Though treatment options are becoming more effective for patients, the treatment process is still a physically, emotionally, and psychologically demanding time period for patients. Patients can often expect many adverse side-effects. Physically, patients may find that they are extremely fatigued, have a loss of appetite, and face constant nausea; not to mention their treatment may cause hair loss and other side-effects. In addition, many patients face depression, anxiety, and a host of other emotional and psychosocial issues (National Cancer Institute, 1999). Depending on the type of cancer and the severity, treatment may last weeks, months, or even years. The National Cancer Institute has realized that this population possesses unique medical, social, physical, and psychological needs, and that these needs are still poorly understood (Meadows et al, 1998). 
Each year researchers across the world investigate ways to lessen the negative impacts that are often associated with cancer treatment. This chapter is a review of just one of the intervention types - interventions that aim to promote increased PA during treatment. The chapter will begin with a short overview of two of the most common treatment modalities. That will be followed by a review of literature pertaining to exercise interventions during the treatment process; specifically details will be provided on the outcomes that have been studied within this line of research and outcomes which warrant investigation will be highlighted. In addition, a brief review of pedometer interventions both with cancer patients and with a "healthy" population will be discussed. The chapter will end with a conclusion.

\section{Treatment options}

The possible cancer treatment options available to cancer patients can at times seem staggering. The National Cancer Institute (NCI) list 14 different types of treatment on their cancer treatment resource page (National Cancer Institute, n.d. (b)). Though there are many treatments being used to combat cancer, this brief review will only focus on two of the most widely used treatment modalities: chemotherapy and radiation (Cancer Treatment Centers of America, 2007). Radiation and chemotherapy are often classified as adjunct treatments since they are mostly used after an initial treatment option, in most cases surgery.

\section{Chemotherapy.}

Chemotherapy is a treatment procedure, which on just name recognition alone, is one of the most widely known treatment processes. Chemotherapy is, generically, the use of drugs to prevent cancer cells from multiplying, invading, metastasizing, and ultimately killing the patient. The process of inhibiting cell multiplication takes places at many different levels within the cell and its environment. Macromolecular (large molecules including proteins, nucleic acids, and 
polysaccharides) synthesis and function; cytoplasmic organization and signal transduction; cell membrane and associated cell surface receptor synthesis, expression, and function; and environment of cancer cell growth represent the four main levels at which chemotherapy agents inhibit the spread of cancer cells. Unfortunately these drugs often attack more than just the cancer cell and since cell multiplication is a normal process of many different types of cells, this can result in many negative consequences. Specifically, most chemotherapy work takes place at the macromolecular level. Since the agents can have trouble differentiating between proteins they often attack the body's healthy proteins, DNA and RNA in particular. Cell death rarely takes place at the initial introduction of the drug so multiple doses of chemotherapy are needed. In real life cases, all cells in any given tumor are not equally sensitive to the drug and the cell sensitivity might change during therapy so the number of sessions can differ greatly between patients in accordance to any number of variables such as cancer type, location, severity etc (Skeel \& Khleif, 2003).

Chemotherapy is a very exact and complicated science and doctors often use a combination of different drugs (combination chemotherapy) to attack certain tumors (National Cancer Institute, 1999). Most times, chemotherapy is received in an outpatient setting, where the patient comes into the hospital/oncology clinic, receives the chemotherapy and then is free to leave at the end of that individual session. Chemotherapy can be administered intravenously (through a vein), orally, given in a shot, or applied directly to the skin. The most often used method is an IV, and depending on the number of sessions a patient has they might receive a catheter, pump, or port to ease the chemotherapy process (National Cancer Institute). Chemotherapy can affect different patients in different ways; some will be able to live their normal life around their sessions, while others will find themselves fatigued and tired after their 
sessions. Chemotherapy can be a very effective treatment process, but as mentioned earlier it can have a number of adverse side effects.

The National Cancer Institute (1999) lists 20 different possible side effects that might arise with chemotherapy; these side effects range from fatigue, to hair loss, to an increased likely hood of infection. Often, the presence of these side effects can lead to a change in the patient's chemotherapy. Measures might be taken to mix in different drugs during chemotherapy to inhibit any given side effect, and often patients will go through multiple drug "cocktails".

Chemotherapy can be a troublesome time for many. Just hearing the names of the drugs alone is enough to cause anxiety and confusion for the patient: Taxol, Bleomycin, Topotecan, Methotrexate, and Asparaginase are just a sample of the different drugs that might be used during this process (Skeel \& Khleif, 2003). Even though there can be many negative outcomes from this process, chemotherapy is often a vital part of a cancer patient's treatment and it is ultimately up to the patient to learn how to cope with this taxing procedure.

\section{Radiation}

Another option that is frequently used during the cancer treatment process is radiation therapy. About 50-60 percent of all cancer patients receive some form of radiation treatment during their treatment process (Radiological Society of North America, 2006). Much like chemotherapy, radiation aims to stop the reproduction of the cancer cells. A source or radiation (X-rays, gamma rays, particle beams, or proton beam therapy) is used to damage the genetic material of the cancer cells with the goal of making it impossible for these cells to grow and divide (National Cancer Institute, 2004). In addition to being used to directly affect cancer cells, radiation is often used to lessen pain. There are three main ways in which radiation is used: external radiation therapy, brachytherapy (internal radiation therapy), and systemic radiation 
therapy (National Cancer Institute). External radiation, either used during actual surgery (intraoperative radiation therapy) when a large dose of radiation is aimed directly at the tumor site, or general external radiation where a machine used to aim radiation at a general location, are the most familiar of the radiation therapies. Internal radiation uses sealed implants of radioactive material that are placed into, or near the tumor site. Systemic radiation therapy used radioactive materials that are either injected into the body or taken orally. The individual radiation sessions are much shorter than chemotherapy sessions, most appointments last 30 minutes with the actual radiation time lasting only three or four; the procedure is painless, and has less side effects than chemotherapy (National Cancer Institute, 1999a). Though the individual sessions are short, radiation is a much more intensive process. A typical radiation regiment will last around two months, with individual sessions being administered five days a week. The side effects of radiation are normally limited to some fatigue.

\section{Exercise during the Cancer Treatment Process}

Within the normal population many of the positive outcomes associated with increased exercise have been known for decades, if not longer. Exercise lowers the risks of many adverse health conditions: strokes, heart disease, diabetes, and many cancers (CDC, 2006). Exercise has been proven to be reduce depression (Carron, Hausenblas \& Estabrooks, 2003; Lox, Martin Gines, \& Petruzzello, 2006), lower anxiety levels (Lox et al), and reduce stress (Carron et al; King, Marcus, Pinto, Emmons, \& Abrams, 1996; Lox et al), and a recent meta-analysis found that one of the outcome variables that exercise positively effects the most is self-efficacy (Netz, Jia-Wu, Becker, \& Tenenbaum, 2005). What is not as well established, and what has only started receiving considerable attention within the last decade is the use of exercise of during the cancer treatment process and the potential positive effects it may have on cancer patients. Before these 
relationships between increased PA and its effects are explored the feasibility of implementing exercise programs will be discussed.

Feasibility of Exercise during Cancer Treatment

During the 1990's, a group of researchers set out to explore how physical active cancer patients were during treatment. To accomplish this goal over 900 prostate and breast cancer patients from across the nation were surveyed, and their responses produced some very interesting results (Demark-Wahnefried, Peterson, McBride, Lipkus, \& Clipp, 2000). Over half (58\%) of all individuals who had been diagnosed with cancer in the five-year period from 19921997 were currently on some form of exercise routine; however only $35 \%$ of all survivors were recommended exercise by their physician. It was also found that over half of the patients would be very interested in a health related program dealing with exercise and that they would have preferred that information to come at the time of, or soon after diagnosis. This study was one of the first to examine the activity levels of patients. The percentage of individuals who reported taking part in activity was relatively high. One of the reasons for this was because all the subjects in this study were at least one year post-diagnosis so many participants may have completed their treatment. While this study's ability to shed light on the activity levels of patients undergoing treatment is weak, the finding that many patients would be receptive to an exercise promotion intervention at the time of, or shortly after their diagnosis helps to build a case that patients are interested in partaking in exercise during the actual treatment process. Not only do patients potentially desire exercise promotions programs, their doctors are not meeting that desire.

In a later study, with a patient population that that had a much more severe type of cancer - head and neck, the activity levels were found to be much lower. It was found that under $9 \%$ of the patients $(n=59)$ were meeting public health guidelines, and only $15 \%$ were at least 
moderately active (Rodgers et al, 2006). The majority of this sample had been diagnosed within the last six-months, making these findings more reflective of patients undergoing treatment. Not only were few patients reporting being active, over half of those surveyed were completely sedentary. Neither this study, nor the study explored prior this are reflective of cancer patients as a whole. The activity levels of patients most likely lies in between these two findings. Though there is some disagreement over the activity levels of patients, it is accepted within the literature that patients do experience a decrease in activity levels during treatment and many patients never return to their pre-diagnosis levels of activity (Courneya \& Friedenreich, 1997 a \& b).

Even though studies have differed in regards to the amount of PA observed with cancer patients, one finding that has been shown in a number of studies is that exercise interventions are feasible with this unique clientele, and they are well tolerated (Conn, et al, 2006; Losito et al, 2006; Schmitz et al, 2005). Both group (Losito et al), and individual exercise interventions (Stevinson, Lawlor, \& Fox, 2004) have been found to be well tolerated and beneficial to patients. Qualitative information gathered in one study of current health behaviors found that the majority of individuals reported a strong preference for exercise programs to be offered in the initial treatment period (Demark-Wahnefried et al, 2000). With this solid background of studies and reviews, the question of whether or not exercise interventions are feasible and tolerable has been answered with a resounding yes.

\section{General Outcomes}

Interventions done with this population have looked at any number of outcome variables. From pain (Mustian et al, 2006), to physical capacity (Quist et al, 2006), the list of variables to include in any given study is quite long. Fatigue is one of the most, if not the most often reported side-effect of cancer treatment and thusly represents one of the most oft studied outcomes of 
exercise interventions, and the results of have been mixed. In a study by Mustian and colleagues, fatigue, along with many other negative side-effects of cancer treatment were looked at. Patients were recruited from all over the country, and were asked to fill out a questionnaire at the beginning of treatment as well as six months post treatment. All exercise was self-reported, and there were no prompts made by the investigators to begin exercising. Intensity, duration, and frequency were not reported, instead anyone who answer yes to the simple question of "Since your cancer diagnosis, have you used exercise?" were counted as exercisers. Fatigue was one of two (the other being shortness of breath) of the side-effects that exercise had a significantly inverse correlation with $(r=-0.09, p<0.05)$. This number improved slightly $(r=-0.12, p<0.05)$ when exercise and side-effects were assessed six months after treatment. Further analyses between fatigue and the amount of exercise one engaged in at six months revealed that there were significant differences between exercise groups $\left(F_{3595}=3.754, p=0.011\right)$. The biggest strength of this study was its sample size, $n=749$. This study quantified an individual as being activity if they simply answered "yes" to exercising. There was no effort made to distinguishing among individuals who exercised regularly or frequently and those that exercise a few times, this may have led to the relatively week correlations. At the very least, this study shows that a sizeable amount of patients are open to the idea of using exercise during and after the treatment process, and structured interventions might be the ideal tool to meet this desire.

Another study of 31 men who have been diagnosed with prostate cancer was done to measure the effects of a PA program on a number of different variables, including fatigue, and produced significant results (Culos-Reed, Robinson, Lau, O'Conner, \& Keats, 2007). Willing participants took part in the Prostate Active Living Series (PALS), which consisted of a homebased exercise program individually tailored and prescribed by a certified fitness professional. 
The intervention lasted 12 weeks, with each participant being asked to exercise three to five times a week. In addition to this prescription, every two-weeks participants had the chance to attend a group session that had both exercise and education/discussion time. Each member was tested pre and post, on a number of measures including fatigue. Fatigue was found to decrease significantly from baseline to post-test $(d=.76)$.

In addition to fatigue, the relationship between exercise and its effect on patients' immune functions represents a line of study within the exercise and cancer literature. Many cancer patients' immune systems start to decline, not only due to their illness but also do to the side-effects of their treatment. As was mentioned earlier, adjunct treatment aims to kill the cancer cells within the body, but at time these treatments not only kill cancer cells but can affect some of they body's healthy cells, specifically white blood cells and other cells which make up the body's natural defense system.

A study by $\mathrm{Na}$ and colleagues aimed to investigate the relationship between mild exercise and immune function (Na, Kim, Kim, Ha, \& Yoon, 2000). Thirty-five stomach cancer patients were recruited for the study; 17 were placed into an experimental group while 18 were used as a control. All the patients were stomach cancer patients who just completed surgery. The experimental group exercised three times a day for thirty minutes while they were recovering in the hospital. These exercises were all done in bed and consisted of pelvic tilting, active range of motion exercises, and isometric quadriceps-setting exercises. Once the patients were able to walk, they were led in supervised exercises on arm and bike ergometers twice a day, five times a week, for two weeks. To measure immune function, blood samples were obtained on the first day following the patients operation, day seven, as well as day 14. Specifically, the blood was drawn 
to examine the natural killer cell cytotoxic activity (NKCA). NKCA is a marker of immune function, and is the first-line host defense against cancer.

There were no mean differences in NKCA between the two groups at baseline (first day after operation) (16.2\% for the experimental group $19.7 \%$ for the control $p>0.05)$ or seven-days post operation ( $14.6 \%$ for the experimental, $17.9 \%$ for the control $p>0.05)$. However, when NKCA was measured 14 days after the patients' operations, it was found that the control groups mean NKCA dropped more than four percentage points $(13.3 \%)$, while the experimental groups rose more than 12 percentage points $(27.9 \%)$; this was the only data collection point were there was a statistical difference between the two groups $(p<0.05)$. In addition, when all the patients were studied together, exercise was the only significant predictor of NKCA increasing from day seven to day $14(p=0.003)$. Though this study's results are encouraging, a few things need to be noted. The level of exercise for the experimental group was quite high; the exercises themselves were mild to moderate, however exercising two or three times a day is quite high. In addition, the authors do not provide any follow-up data, so it is unknown how long the differences between the two groups lasted. Even when some of the weaknesses of this study are taken into account, the results are still promising and warrant further exploration.

In another study investigating exercise and immunological functioning, researchers chose $\mathrm{CD}^{+}$cells as their marker of choice (Hutnick et al, 2005). These cells, T-helper cells (a type of white blood cells) were chosen because during cancer these cells often see the largest decrease in numbers, and they are often the slowest to rise in numbers. In addition, not only do CD4 ${ }^{+}$ decrease in numbers the ones that remain are often less active making the patient more susceptible to infection. To study the effects of exercise on these cells the researchers recruited 49 breast cancer patients. Twenty-eight were placed into an experimental group, while 21 were 
placed into a standard treatment control group. All patients received physician approval and had been finished with their cancer treatment for at least two-weeks. The experimental group met with a physical trainer three times a week for six months and did both anaerobic and aerobic exercises for 40-90 minutes, however 10 women choose to work on their own for the last three months but they were contacted weekly by their trainer. Overall the compliance rate for the experimental group was $82.2 \%$ for the firth three months and $75.9 \%$ for the remaining three months. Blood samples and fitness measures were taken at post-treatment (T1), three months (T2), and six months (T3). There were no differences between the two groups on any significant variables at baseline.

At the end of the intervention, T3, the experimental group fitness scores were significantly higher than the control groups. Fitness was measured using $\mathrm{VO}_{2 \max }$, bicep and tricep curls, and grip tests. The experimental group scored higher on all measures. In regards to $\mathrm{CD} 4^{+}$cells, there were no differences in numbers between the two groups at any test point, and at all test points both groups were well under the healthy average. However, within the experimental group, the $\mathrm{CD}^{+}$cells that were present were shown to be more active than the control group. Though there was no increase in numbers, the $\mathrm{CD} 4^{+}$cells within the experimental group were more adept at warding off infection than the control group. This study's findings help to build the case that exercise with cancer patients can help immunological functioning. Though the researchers didn't find an increase in cell numbers, the increase in cell activity is very significant as cancer survivors often experience secondary infections during/following treatment. There are a few inherent issues with this study. By utilizing a mixed aerobic and anaerobic exercise intervention it is unclear if a certain type of exercise is more beneficial. If the researchers would have used a mixed group, a strictly aerobic group, and a strictly anaerobic 
group the effect of type of exercise could be teased out. Though this weakness, and others exist with this study, there were many strengths that make the findings even more significant. The researchers were able to recruit very comparable groups, which helps the generalizablity of the findings. This study and the one mentioned prior, help to begin a case that exercise can be beneficial for immunological functioning for cancer patients. As the literature evolves in the coming years, immune functioning needs to be a continued variable of study.

\section{Quality of Life}

One of the most prevalent outcomes studied in this field is QOL. QOL can be thought of as a patient's assessment of the impact their cancer diagnosis and treatment has on their physical, psychological, and social functioning (Aaronson et al, 1993). Often QOL is measured by assessing the person's ability, or their perception of their ability to carry out various activities (i.e. getting dressed, maintaining a normal work routine) (National Cancer Institute, n.d. (a)). Since QOL is multi-faceted, most instruments that measure QOL cover many components. QOL measures may have sub-scales for physical functioning, emotional functioning, social functioning etc. There are a number of different QOL instruments available to researchers. Many are specific to cancer type, while others are specific to the time frame in which patients reside (i.e. treatment or rehabilitation). It is beyond the scope of this paper to discuss the differences between instruments with great depth. Regardless of the instrument chosen, QOL has been a widely looked at outcome within not only the cancer and exercise literature, but within the general cancer survivorship literature as well.

One of the reasons why QOL is often looked at within the exercise and cancer literature is because physical functioning is often a large part of QOL. Hypothetically, if exercise can increase physical functioning, then exercise can increase QOL. One studied showed just that. 
Using prostate patients who were receiving radiation, Monga and colleagues set out to determine if a supervised aerobic exercise routine improved quality of life (Monga et al, 2007). Using only first time patients, 21 participants were recruited and placed into either the structured exercise intervention group or a control group which received standard care. Both groups had members who exercised at least two times a week, and members who did not engage in any exercise. The intervention group exercised prior to the radiation appointments three times a week in the cancer center where they were receiving radiation. Their exercise routine consisted of a 10 minute warm up, 30 minutes of walking on a treadmill, and a five to 10 minute cool down period and they were assigned a target heart rate which they were to maintain. All individuals were measured on a number of variables prior to their radiation regimen, and after their treatment. There were no differences between the two groups in regards to a number of variables including, but not limited to, age, weight, and ethnicity.

There were no between group difference on any of the outcome variables at pretest; at posttest there were several differences between the exercisers and the standard care individuals. The intervention group scored higher on measures of physical functioning including a stand-andsit test $(t=-4.73, p=0.00)$, flexibility $(t=2.73, p<0.01)$, and fatigue $(t=-4.72, p<0.001)$. In regards to QOL, the control group had a lesser overall score $(t=3.12, p=0.006)$, and scored lower on the physical, social, and functional well-being subscales $(t=4.19, p<0.001 ; t=3.47, p$ $<0.002$; and $t=2.24, p<0.04$ respectively). These results may indicate, that even a short intervention (eight weeks) promoting mild to moderate exercise may be able to produce advantageous results. The participants who received the intervention not only improved their physical functioning; they improved their QOL across a number of components (i.e. physical and social). Though the sample size was quite small, significant findings were found. In addition, this 
study represents the only study to utilize a randomized control trial with prostate patients undergoing adjunct treatment.

A slightly larger study, this time with women, produced similar results. A sample of 34 breast cancer survivors over the age of 50 were recruited to investigate the effect of an exercise intervention on a number of variables, including QOL — specifically health related QOL (Damush, Perkins, \& Miller, 2006). For their study, the researchers employed a single group pretest-posttest design with an intervention that consisted of an exercise self-management program. Individuals who consented to take part in the study were able to attend three weekly self-management sessions, which aimed to increase exercise self-efficacy. The participants were prescribed a walking program that started off having individuals walking at a brisk rate 30 minutes a day twice a week, then increasing to six times a week. In addition strength exercises were recommended twice a week. Patients also received phone calls four weeks, six weeks, and 10 weeks into the intervention. The content of the weekly meetings and the phone calls were developed from focus groups and focused on constructs such as goal-setting and behavioral contracts. In addition to measuring health related QOL using the Cancer Rehabilitation Evaluation System-Short Form, the researchers looked at both fatigue and depressive symptoms, which many would argue, are components of QOL. Upon enrollment, participants filled out measures for all of the study's outcome variables, and this collection represents the baseline collection point.

Participants were measured again after six months, which represents the posttest data collection point. At posttest, participants reported an increase in PA across a number of areas; individuals increased their frequency of leisurely walks $(d=0.82)$ and increased the amount of time they spent walking briskly each week $(d=0.34)$. In addition to changes in PA levels, 
differences were found in regards to all components of health related QOL. Depressive symptoms and fatigue decreased over $20 \%$ ( $d=0.46 \& d=0.45$ respectively). Physical and psychosocial functioning both increased as well $(d=0.49 \& d=0.31)$. These finds are very encouraging. It seems that as PA levels increase, QOL improves. However, this study has some weaknesses that need to be addressed in future research. All PA levels were reported using recall; there was no objective data collected in regards to the amount and intensity of activity being completed. The researchers also failed to show any relation between higher levels of activity and better improvements in QOL. Perhaps if they would have split the subjects between those who reported being active at a certain level and those who failed to reach that level, they would have seen differences in QOL between the two groups. In addition, the lack of a control group hurts this study's ability to claim that PA helped to increase QOL, the rise in QOL might have been a simple function of time. Even with these considerations, this study begins to make an argument that exercise does indeed have positive effects on QOL.

Another study that adds to this argument was done by Mock and colleagues (Mock et al, 2001). In their study, the researchers recruited 52 female breast cancer patients. All the women recruited were just beginning their adjunct treatment (radiation $=30$, chemotherapy $=18$ ). The mean age of the participants was 48 , and $94 \%$ were diagnosed with either stage I or stage II cancer. The participants were randomly assigned to either an investigational walking group or a control group. Those in the walking group were given a booklet outlining a walking program, and had an exercise prescription explained to them at their cancer clinic. All prescriptions were individualized; most began with 10 to 15 minutes of walking five to six times a week, then increased to 30 minutes a session five to six times weekly. Participants' interventions lasted as long as their treatment. The control group received no such information. All individuals were 
measured at baseline as well as the conclusion of their treatment on a number of variables including physical functioning measured via a 12-min walking test and the activity level rating scale, individuals also filled out the Profile of Mood States (POMS) to measure emotional distress, and QOL was measured using the MOS SF-36. In addition all patients filled out diary's recording their activity levels.

Prior to running their data analysis, Mock and colleagues realized that some of the individuals within the control were very active, while some members of the walking group were relatively inactive. Due to this, instead of comparing the walking group to the control group, they split all the participants into a high walking group (more than 90 minutes a week) and a low walking group (less than 90 minutes a week). Though this effectively proved their intervention to not be effective, significant results emerged between these two groups. Individuals within the low walking group saw their levels of PA drop, while individuals in the high group saw their levels rise $(p<0.01)$. Women in the high group also reported significantly less levels of general mood disturbance (-1.00 vs. 18.52). The high walking group also had significant decreases in anxiety $(t=3.32, p=0.00)$ and depression $(t=2.00, p=0.03)$ while the low walking group saw no such decline. At the end of the treatment, both groups had lower levels of QOL, however, the low walking group's scores dropped 48\% $(p=0.00)$ while the higher group saw their scores drop $16 \%(p=0.02)$.

Unlike the previous study, this study looked at patients undergoing treatment. The findings suggest that increased levels of PA have a number of positive outcomes. Though this study utilized a control group, when the data was analyzed, the groups were combing then resplit in regards to activity level. All activity levels were reported using self-recall, which is a major limitation. In addition, some of the patients had undergone treatment before, which 
represents an extraneous variable that might have needed to be controlled. Even though their intervention failed to provide enough of a difference in activity levels in comparison to a control group, this study's findings give credence to the idea that there is a positive correlation between activity levels and QOL. Self-efficacy for Coping with Cancer.

In the previous two sections, some of the most popular outcomes were briefly looked at; this section deals with an outcome that is studied much less. Self-efficacy is widely considered to be a key psychological resource in adapting to chronic illness, but has received little attention among individuals coping with cancer (Manne et al, 2006). It's only natural to believe that higher levels of self-efficacy in any task will lead to better outcomes, in the social cognitive model individuals with higher self-efficacy beliefs can call upon these believes and abilities to manage the task at hand. Though it inherently seems to be an important psychological construct for cancer patients, very few studies have studied self-efficacy for coping with cancer.

Beckham and Burker put out a study in 1997 that studied the relationship between cancer self-efficacy and a number of different variables. They used the Cancer Self-Efficacy Scale (SE), which has three domains: pain (e.g., "How certain are you that you can decrease your pain quite a bit"); function (e.g., "As of now, how certain are you that you ca walk $100 \mathrm{ft}$ on flat ground in 20 seconds?"), and other symptoms (e.g. How certain are you that you can control your fatigue?"). Individuals rate the items from very uncertain to very certain. They randomly selected 52 male veteran outpatients with cancer to participate in the study, and $42(n=42)$ consented. Once consent was received, the participants were asked to complete a packet of questionnaires that included all the measures. A series of correlations were run to detect relationships between scores on SE and other measures. Significant relationships were found between SE and the 
following variables: cancer adjustment (lower scores relate to better adjustment) $(r=-.59$, $p<.001)$; negative affect $(r=-.52, p<.001)$; psychological distress $(r=-.52, p<.001)$, and behavioral dysfunction $(r=-.53, p<.001)$. In this sample of cancer patients, higher self-efficacy for coping with cancer scores related to other desirable positive psychological conditions.

A comparable study, done in Japan produced similar results. Hirai and colleagues set out to test relationships between self-efficacy for coping with cancer and a number of variables including depression and anxiety with advanced cancer patients $(n=85)$ (Hirai et al, 2002). Patients filled out the scale of Self-Efficacy for Advanced Cancer (SEAC), and the Hospital Anxiety and Depression Scale (HADS). The SEAC has three subscales, symptom coping efficacy (SCE), activities of daily living efficacy (ADE), and affect regulation efficacy (ARE). All three subscales had significant correlations with depression $(\mathrm{SCE}=-0.31 ; \mathrm{ADE}=-0.54 ; \mathrm{ARE}=-$ 0.49 ; all at $\mathrm{p}<0.01)$ and anxiety $(\mathrm{SCE}=-0.24 ; \mathrm{ADE}=-0.44 ; \mathrm{ARE}=-0.42$; all at $\mathrm{p}<0.01)$. In addition to running these correlations, the researchers used a structural equation model in which selfefficacy for coping with cancer accounted for just under $65 \%$ of emotional distress by patients. Much like Beckham and Burker's (1997) work, this sample produced results that showed a strong relationship between low self-efficacy scores and high occurrence of emotional distress, which would in turn lower QOL.

\section{Pedometer Interventions}

To the best of this researcher's knowledge, there has only been one study that used pedometers with cancer as a means of intervention. This study, run by Vallance and colleagues (Vallance, Courneya, Plotikoff, \& Mackey, 2008), focused on self-report recall measures of activity. Their study consisted of four groups: one receiving a standard PA recommendation, one who received printed materials on raising PA levels, one which received a pedometer and step- 
count calendar, and one received the same materials as both the pedometer and printed materials groups. All groups were instructed to wear their pedometers for the first week, and the last week of the intervention (week 12). Only the pedometer group was told to wear their pedometer for the full 12 weeks. There were no differences seen in the number of steps taken at baseline and at post-test for any of the four groups. However, the pedometer group did see an increase in selfreported brisk walking from 69 minutes a week $(\mathrm{SD}=118)$ to 162 minutes a week $(\mathrm{SD}=221)$ at post-test $(p=0.006)$. It is interesting that the researchers elected to run a pedometer intervention that consisted of nothing more than providing a pedometer and step-count calendar; plus all groups were given a pedometer but only one received instructions to wear it. No step goals were provided and no information in regards to an ideal step-count were made available. The lack of this information may explain why an increase was not found. Simplifying providing a measurement tool might not be enough of an intervention to provoke change. Though this study failed to promote an increase in PA through an increase in daily steps, it was found that among the 187 individuals who were instructed to keep daily step-counts participants kept these counts $83.3 \%$ (70 out of 84 days) of the time.

Though the use of pedometer interventions within the cancer literature is scarce, pedometers have been used widely by researchers looking to develop and evaluate interventions to raise PA. A recent review of 26 studies by Bravata et al. synthesizes much of the data that has come from these studies (2007). In randomized controlled trials (RCTs), pedometer users (users implying that the participants were able to observe their own step-counts) significantly increased their steps per day by almost 2,500 more than their counterparts in control groups ( $95 \%$ confidence interval, $p<.001)$. When considering both RCTs and observational studies, pedometer users increased their step counts by over a quarter $(26.9 \%)$. One of the most 
significant findings from this study is that the use of step-goals was the most significant predictor of increased PA as measured by step-counts $(p=0.001)$.

One study used the notion that step-goals help to increase PA as the basis for intervention (Wyatt et al, 2004). The researchers' goal was to increase the average number of steps taken per day by residents of Colorado by 2,000 steps. The step goal chosen, 2,000, was chosen because an increase in 2,000 steps per day (or roughly a mile) represents an energy expenditure of about 80 to $100 \mathrm{kcal}$ per day. It is hypothesized that if individuals increase their daily energy deficient by $80 \mathrm{kcal}$ per day, they will be able to maintain their weight; stopping the average yearly weight gain of one pound. The researches created a 14 week walking intervention based around the tracking of steps and the providence of step-goals. To test their intervention the researchers used six work sites to recruit 503 individuals.

It was found that average daily step counts rose from 7,669 $(n=450)$ (subject error mean, $\mathrm{SEM}=143)$ to $10,417(n=270, \mathrm{SEM}=275)$. It was also found, that during the last four weeks, around half of all participants $(n=146)$ who completed all the phases of the study had average daily step-counts which were at least 2,000 steps per day higher than their baseline average. These findings indicate that for individuals who complete the intervention were likely to increase their steps significantly. Findings such as this lend strength to the notion that an inexpensive intervention using pedometers can be an efficacious means of increasing PA. This study was limited to one state, and the most active state-Colorado. In addition, all participation was voluntary; it was voluntary for worksites to join the study and it was voluntary for the individual employees to join. This obviously led to a volunteer bias. This study is a pilot for a larger scale project, and its findings are encouraging. If the larger project can produce similar results, then the efficacy of pedometer interventions will only be increased. 
Not only have interventions utilizing pedometers been proven to be efficacious, studies have shown that beneficial outcomes can arise even when using a short intervention time frame. In a study with type 2 diabetes mellitus participants $(n=30)$, individual were placed into either an experimental group which were instructed to walk 10,000 or more steps five or more days a week, or into a control group which was told to maintain their normal activity levels (Araiza, Hewes, Gashetewa, Vella, \& Burge, 2006). Both groups tracked their PA levels (as measured by step-counts) for six weeks. At the end of this time period, participants in the experimental group increased their steps almost $70 \%$, or on average, 10,410 steps $(\mathrm{SD}=4,162, p=0.002)$. There was no increase in step counts amongst the control group. In addition to increasing their PA levels, the experimental group also experienced an increase in high-density lipoprotein cholesterol (HDL-C), while the control group saw no such increase. These findings help to strengthen the notion that pedometers can play a very useful role in PA interventions.

\section{Conclusion and Recommendations for Future Research}

Research has shown that not only are PA interventions tolerable with cancer patients, they are often desired (Demark-Wahnefried et al, 2000). Many interventions have also produced promising results. Including reductions in fatigue (Mustian et al, 2006), increases in physical capacities (Damush et al, 2006; Monga et al, 2007), and increases in QOL (Mock et al, 2001; Monga et al). Though much of the findings in the literature are encouraging, there are some issues that need to be addressed with future research.

Many of the reviews of literature have called for more stringent and sound methods (Courneya, 2003; van Weert et al, 2007). A good portion of the recent work within this field has taken this to heart; the number of randomized control trials has increased in recent years. This trend needs to continue. Another way to improve upon the methodological approaches within 
this field is to lessen the reliance on self-report recall measures of PA. Almost all of the studies done have used some form of recall to record time spent in PA. Just as many interventions with the general population have started to track activity via pedometers and accelerometers, the cancer and exercise work needs to follow suit. Pedometers have been proven to be cost-effective, simple to use, and reliable (Bravata et al, 2006); and the inclusion of these devices would be a simple supplement to many interventions.

Much work has been done in regards to the relationship between QOL and increased levels of PA. It is now established that there is indeed a positive relationship (Mock et al, 2001; Monga et al, 2007). What is less known, is the type and duration of activity that has the most beneficial effect on QOL. It is also unclear as to what might mediate this relationship. It has been hypothesized that increased functioning plays a large role in this relationship, which is most likely true. However, there most likely are other mediators. For instance, PA may raise selfefficacy, which in turn raises QOL. Further work needs to be done to better understand the relationship between QOL and exercise.

For a body of literature that is still relatively young, exercise interventions with cancer patients have been shown to be effective and efficacious. More work is needed, and it is clear that many steps are being taken to strengthen future studies. As methodological approaches improve, and as the relationship between PA and improvements across a number of spectrums becomes clearer, it is very possible that exercise interventions may become a standard part of the cancer treatment process. 


\section{REFERENCES}

Aaronson N.K, Ahmedzai S, Bergman B, Bullinger M, Cull A, Duez N.J, et al. (1993) The European organization for research and treatment of cancer QLQ-C30: A quality-of-life instrument for use in international clinical trials in oncology. Journal of the National Cancer Institute 85, 365-376.

Ahmedin, J., Siegel, R., Ward, E., Hao, Y., Xu, J., Murray, T., et al. (2008) Cancer statistics, 2008. CA: A Cancer Journal for Clinicians, 58, 71-963.

American Cancer Society (2007). Cancer facts and figures 2006. American Cancer Society. Retrieved February 7 2007, from http://www.cancer.org/downloads/STT/CAFF2007PWSecured.pdf.

Araiza, P., Hewes, H., Gashetewa, C., Vella, C.A., \& Burge, M.R. (2006). Efficacy of a pedometer-based physical activity program on parameters of diabetes control in type 2 diabetes mellitus. Metabolism Clinical and Experimental, 55, 1382-1387.

Beckham, J.C., \& Burker, E.J. (1997). Self-efficacy and adjustment in cancer patients: A preliminary report. Behavioral Medicine, 23 138-142.

Bravata, D.M., Smith-Spangler, C., Sundaram, V., Gienger, A.L., Lin, N., Lewis, R. et al. (2007). Using pedometers to increase physical activity and improve health: A systematic review. JAMA, 19, 2296-2304.

Bren, L. (2007) Cancer drugs: Weighting the risks and benefits. FDA Consumer Magazine (Online Article). Retrieved April 11, 2007, from http://www.fda.gov/fdac/features/2007/107 cancer.html

Carron, A.V., Hausenblas, H. A., \& Estabrooks, P.A. (2003). The Psychology of Physical Activity. New York, NY: McGraw Hill. 
Cancer Treatment Centers of America (2007). Conventional cancer treatments. Retrieved March 14, 2007, from http://www.cancercenter.com/conventional-cancer-treatment.cfm Center of Disease Control (2006). Why Should I Be Active? Retrieved April 11, 2007, from http://www.cdc.gov/nccdphp/dnpa/physical/importance/why.htm

Conn, V.S., Hafdahl, A.R., Porock, D.C., McDaniel, R., \& Nielsen, P.J. (2006). A meta-analysis of exercise interventions among people treated for cancer. Support Care Cancer 14, 699712.

Courneya, K.S. \& Friedenreich, C.M. (1997a). Relationship between exercise during treatment and current quality of life among survivors of breast cancer. Psychosocial Oncology, 15, $35-37$.

Courneya, K.S. \& Friedenreich, C.M. (1997b). Relationship between exercise pattern across the cancer experience and current quality of life in colorectal cancer survivors. Alternative Complementary Medicine, 3, 215-226.

Culos-Reed, S.N., Robinson, J.L., Lau, H., O’Connor K., \& Keats, M.R. (2007). Benefits of a physical activity intervention for men with prostate cancer. Journal of Sport \& Exercise Psychology, 29, 118-127.

Damush, T.M., Perkins, A., \& Miller, K. (2006). The implementation of an oncologist refereed, exercise self-management program for older breast cancer survivors. Psycho-Oncology, 15, 884-890.

Demark-Wahnefried, W., Peterson, B., McBride, C., Lipkus, I., \& Clipp, E. (2000). Current health behaviors and readiness to pursue life-style changes among men and women diagnosed with early stage prostate and breast carcinomas. Cancer, 88(3), 674-684. 
Hirai, K., Suzuki, Y., Tsuneto, S., Ikenaga, M., Hosaka, T., \& Kashiwagi, T. (2002). A structural model of the relationships among self-efficacy, psychological adjustment, and physical condition in Japanese advanced cancer patients. Psycho-Oncology, 11, 221-229.

Hutnick, N.A., Williams, N.I., Kraemer, W.J., Orsega-Smith, E., Dixon, R.H., Bleznak, A.D. \& Mastro, A.M. (2005). Exercise and lymphocyte activation following chemotherapy for breast cancer. Medicine and Science in Sport and Exercise, 37, 1827-1835.

King, T.K., Marcus, B.H., Pinto, B.M., Emmons, K.M., Abrams, D.B. (1996). CognitiveBehavioral mediators of changing multiple behaviors: Smoking and a sedentary lifestyle. Preventive Medicine, 25, 684-691.

Losito, J.M., Murphy, S.O., Thomas, M.L. (2006). The effects of group exercise on fatigue and quality of life during cancer treatment. Oncology Nursing Forum, 33 (4), 821-825.

Lox, C., Martin Gines, K. A., \& Petruzzello, S.J. (2006). The Psychology of Exercise Integrating Theory and Practice. Scottsdale, AZ: Holcomb Hathaway.

Manne, S.L, Ostroff, J.S., Norton, T.R., Fox, K., Grana, G., \& Goldstein, L. (2006). Cancerspecific self-efficacy and psychosocial and functional adaptation to early stage breast cancer. Annals of Behavioral Medicine, 31, 145-154.

Meadows, A.T., Varricchio, C., Crosson, K., Harlan, L., McCormick, P., Nealon, E., Smith, M., \& Ungerleider, R. (1998). Research issues in cancer survivorship: Report of a workshop sponsored by the office of cancer survivorship, national cancer institute. Cancer Epidemiology, Biomarkers \& Prevention, 7(12), 1145-1151.

Mock, V., Pickett, M., Ropka, M.E., Muscari Lin, E., Stewart, K.J., Rhodes, V.A. et al. (2001). Fatigue and quality of life outcomes of exercise during cancer treatment. Cancer Practice, 9, 119-127. 
Monga, U., Garber, S.L., Thornby, J., Vallbona, C., Kerrigan, A.J., Monga, T.N. et al. (2007). Exercise prevents fatigue and improves quality of life in prostate cancer patients undergoing radiotherapy. Archives of Physical Medicine Rehabilitation, 88, 1416-1422.

Mustian, K.M., Griggs, J.J., Morrow, G.R., McTiernan, A., Roscoe, J.A., Bole, C.W., Atkins, J.N., \& Issel, B.F. (2006). Exercise and side effects among 749 patients during and after treatment for cancer: a University of Rochester cancer center community clinical oncology program study. Support Care Cancer, 14, 732-741.

Na, Y., Kim, M., Kim, Y., Ha, Y., \& Yoon, D.S. (2000). Exercise therapy effect on natural killer cell cytotoxic activity in stomach cancer patients after curative surgery. Archives of Physical Medicine Rehabilitation, 81, 777-779.

National Cancer Institute, (2004). Radiation therapy for cancer: Questions and answers. Retrieved March 15, 2007, from http://www.cancer.gov/cancertopics/factsheet/Therapy/radiation.

National Cancer Institute, (1999). Chemotherapy and you: A guide to self-help during cancer treatment. Retrieved March 14, 2007 from http://www.cancer.gov/cancertopics/chemotherapy-and-you/page2

National Cancer Institute, (1999a). Radiation therapy and you: A guide to self-help during cancer treatment. Retrieved March 15, 2007 from http://www.cancer.gov/cancertopics/radiation-therapy-and-you/page3

National Cancer Institute, (n.d. (a)). Dictionary of cancer terms. Retrieved February 9, 2007, from http://www.cancer.gov/dictionary/. 
Netz, Y., Wu, M., Becker, B.J., Tenenbaum, G. (2005). Physical activity and psychological well-being in advanced age: A meta-analysis of intervention studies. Psychology and Aging, 20, 272-284.

Quist, M., Rorth, M., Zacho, M., Andersen, C., Moeller, T., Midtgaard J., \& Adamsen L. (2006). High-intensity resistance and cardiovascular training improve physical capacity in cancer patients undergoing chemotherapy. Scandinavian Journal of Medicine \& Science in Sports. 16, 349-357.

Radiation Society of North America, (2006). Introduction to cancer therapy (radiation oncology). Retrieved March 15, 2007 from http://www.radiologyinfo.org/en/pdf/intro_onco.pdf

Rodgers, L.Q., Courneya, K.S., Robbins, K.T., Malone, J., Seiz, A., Koch, L., Rao, K., Nagarkar, M. (2006). Physical activity and quality of life in head and neck cancer survivors. Support Care Cancer, 14, 1012-1019.

Schmitz, K.H., Holtzman, J., Courneya, K.S., Masse, L.C., Duval, S., Kane, R. (2005). Controlled physical activity trials in cancer survivors: A systematic review and metaanalysis. Cancer Epidermal Biomarkers \& Prevention 14 (7), 1588-1595.

Skeel, R.T., \& Khleif, S.N. (2003). Biologic and pharmacologic basis of cancer chemotherapy. Skeel, R.T. Handbook of Cancer Chemotherapy Sixth Ed. (3-25). Philadelphia: Lippincott Williams \& Williams.

Stevinson, C., Lawlor, D.A., \& Fox, K.R. (2004). Exercise interventions for cancer patients: Systematic review of controlled trials. Cancer Causes and Control 15, 1035-1056. 
Vallance, J.K.H., Courneya, K.S., Plotnikoff, R.C, \& Mackey, J.R. (2008). Analyzing theoretical mechanisms of physical activity behavior change in breast cancer survivors: Results from the activity promotion (ACTION) trial. Annals of Behavioral Medicine, 35, 150-1583.

Wyatt, H.R., Peters, J.C., Reed, G.W., Grunwald, G.K., Barry, M., Thompson, H. et al. (2004). Using electronic step counters to increase lifestyle physical activity: Colorado on the move ${ }^{\mathrm{TM}}$. Journal of Physical Activity and Health, 1, 181-190. 
Appendix B: CBI

\section{CANCER B E H A IOR I NVENTORY (CBI-B)}

This questionnaire contains many things that a person might do when receiving treatment for cancer. We are interested in your judgment of how confident you are that you can accomplish those things. Make sure your ratings accurately reflect your confidence whether or not you have done it in the past. So, your ratings reflect your confidence that you can do these things now (or in the near future).

Please read each numbered item. Then rate that item on how confident you are that you can accomplish that behavior. Circle a number on the scale. If you circle a "l" you would be stating that you are not at all confident that you can accomplish that behavior. If you circle a " 9 " you would be stating that you are totally confident that you can accomplish that behavior. Numbers in the middle of the scale indicate that you are moderately confident that you can accomplish that behavior.

Please rate all items. If you are not sure about an item please rate it as best you can.

1. Maintaining independence.

2. Maintaining a positive attitude.

3. Maintaining asense of humor.

4. Expressing negative feelings abont cancer.

5. Using denial.

6. Maintaining work activity.

7. Remaining relaxed throughout treatments and not allowing scary thoughts to upset me.

8. Actively participating in treatment decisions.
NOT AT ALL
CONFIJENT

2

Not AT ALL

CONFIDENT$$
\text { ] }
$$

NOT AT ALI.
CONFIDENT

1

NOT AI ALE
CONLIDENT

CONHIDEN

NOT AT ALA.

CONFIBENT

1

NOT AT ALL

CONEIDENT

1

NOT AT ALL

CONFIDENT

1

NOT AT ALL

CONFIDENT'

1
MODERATEly

CONIIDENT

5

6

7

8

TOTALLY CONFIUENT 9

MODERATELY
CONHIDENT

4

5

23

6

7

8

TOTALLY CONFIDENT 9

MODERATELY CONFIDENT

23

4

5

6

7

8

TOTALLY

CONFIDENT 9

MODLRATH.Y CONHIDENT

23

4

5

6

7

TOTALLY Conribent 9

MODERATELY
CONJIIDENT
$4 \quad 5$

23

4

6

7

TOTALLY CONFIDENT 9

MODERATELY CONFIDENT

23

4

5

6

7

TOTALLY CONFIDENT

9

MOUERATELY CONFIDFNT

23

4

5

6

7

TUTALLY CONFIDENT

9

MODERATELY CONFIIJENT

23

4

\begin{abstract}
5
\end{abstract}
6
TOTALLY CONFIDENY 9 
9. Asking physicians questions.

10. Seeking consolation.

11. Sharing feelings of concern.

12. Managing nausea and vomiting.

13. Coping with physical changes.

14. Remaining relaxed while waiting at least one hour for my appointment.
NOTATALI.
CONFIDENT

ONFID

NOTAT ALE

NOT AT ALL
CONFIDENT

CONFID
1

2

Not AT ALL.

CONFIDENT

$$
1
$$

NOT AT AL

CONFIONEN

1

2

NOT AT ALL

CONFIDENT

3

3

3

3

4

(n)

123

\begin{tabular}{|c|c|c|c|c|c|}
\hline \multirow[b]{2}{*}{4} & \multicolumn{4}{|l|}{$\begin{array}{l}\text { MOBOHRATELY } \\
\text { CONFIDENT }\end{array}$} & $\begin{array}{l}\text { TOTALLY } \\
\text { CONFIDENT }\end{array}$ \\
\hline & 5 & 6 & 7 & 8 & 9 \\
\hline & $\begin{array}{l}\text { MODERATELY } \\
\text { CONFIDEN] }\end{array}$ & & & & $\begin{array}{l}\text { TOTALLY } \\
\text { CONFIDENT }\end{array}$ \\
\hline 4 & 5 & 6 & 7 & 8 & 9 \\
\hline & $\begin{array}{c}\text { MODERATELY } \\
\text { CONFIDLI:T }\end{array}$ & & & & $\begin{array}{l}\text { TOTALLY } \\
\text { CONFIDENT }\end{array}$ \\
\hline 4 & 5 & 6 & 7 & 8 & 9 \\
\hline & $\begin{array}{l}\text { MODFRATELY } \\
\text { CONFIDENT }\end{array}$ & & & & $\begin{array}{c}\text { TOTALLY } \\
\text { CONFIOENT }\end{array}$ \\
\hline 4 & 5 & 6 & 7 & 8 & 9 \\
\hline & $\begin{array}{l}\text { MODERATEI.Y } \\
\text { CONFIDEAT }\end{array}$ & & & & $\begin{array}{l}\text { TOTALLY } \\
\text { CONFIDH:NT }\end{array}$ \\
\hline 4 & 5 & 6 & 7 & 8 & 9 \\
\hline & $\begin{array}{l}\text { MODERATELY } \\
\text { CONIIDENT }\end{array}$ & & & & $\begin{array}{l}\text { TOTALLY } \\
\text { CONFIDENT }\end{array}$ \\
\hline 4 & 5 & 6 & 7 & 8 & 9 \\
\hline
\end{tabular}




\section{Appendix C: EO-QOL}

ENGLISH

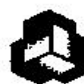

EORTC QLQ-C30 (version 3)

We are interested in some things about you and your health. Please answer all of the questions yourself by circling the number that best applies to you. There are no "right" or "wrong" answers. The information that you provide will remain strictly confidential.

Please fill in your initials:

Your birthdate (Day, Month, Year):

Today's date (Day, Month, Year):
31

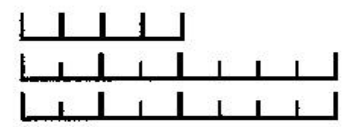

1. Do you have any trouble doing strenuous activities, like carrying a heavy shopping bag or a suitcase?

2. Do you have any trouble taking a long walk?

3. Do you have any trouble taking a short walk outside of the house?

4. Do you need to stay in bed or a chair during the day?

5. Do you need help with eating, dressing. washing yourself or using the toilet?

$\begin{array}{cccc}\begin{array}{c}\text { Not at } \\ \text { All }\end{array} & \begin{array}{c}\text { A } \\ \text { Little }\end{array} & \begin{array}{c}\text { Quite } \\ \text { a Bit }\end{array} & \begin{array}{r}\text { Very } \\ \text { Much }\end{array} \\ 1 & 2 & 3 & 4 \\ 1 & 2 & 3 & 4 \\ 1 & 2 & 3 & 4 \\ 1 & 2 & 3 & 4 \\ 1 & 2 & 3 & 4\end{array}$

\section{During the past week:}

6. Were you limited in doing either your work or other daily activities?

$\begin{array}{cccc}\text { Not at } & \text { A } & \text { Quite } & \text { Very } \\ \text { All } & \text { Little } & \text { a Bit } & \text { Much }\end{array}$

7. Were you limited in pursuing your hobbies or other leisure time activities?

8. Were you short of breath?

9. Have you had pain?

10. Did you need to rest?

11. Have you had trouble sleeping?

12. Have you felt weak?

13. Have you lacked appetite?

14. Have you felt nauseated?

15. Have you vomited?

16. Have you been constipated?

$\begin{array}{llll}1 & 2 & 3 & 4 \\ 1 & 2 & 3 & 4 \\ 1 & 2 & 3 & 4 \\ 1 & 2 & 3 & 4 \\ 1 & 2 & 3 & 4 \\ 1 & 2 & 3 & 4 \\ 1 & 2 & 3 & 4 \\ 1 & 2 & 3 & 4 \\ 1 & 2 & 3 & 4 \\ 1 & 2 & 3 & 4 \\ 1 & 2 & 3 & 4\end{array}$




\section{During the past week:}

17. Have you had diarrhea?

18. Were you tired?

19. Did pain interfere with your daily activities?

20. Have you had difficulty in concentrating on things, like reading a newspaper or watching television?

21. Did you feel tense?

22. Did you worry?

23. Did you feel irritable?

24. Did you feel depressed?

25. Have you had difficulty remembering things?

26. Has your physical condition or medical treatment interfered with your family life?

27. Has your physical condition or medical treatment interfered with your social activities?

28. Has your physical condition or medical treatment caused you financial difficulties?

$\begin{array}{cccc}\begin{array}{c}\text { Not at } \\ \text { All }\end{array} & \begin{array}{c}\text { A } \\ \text { Little }\end{array} & \begin{array}{c}\text { Quite } \\ \text { a Bit }\end{array} & \begin{array}{c}\text { Very } \\ \text { Much }\end{array} \\ 1 & 2 & 3 & 4 \\ 1 & 2 & 3 & 4 \\ 1 & 2 & 3 & 4 \\ 1 & 2 & 3 & 4 \\ 1 & 2 & 3 & 4 \\ 1 & 2 & 3 & 4 \\ 1 & 2 & 3 & 4 \\ 1 & 2 & 3 & 4 \\ 1 & 2 & 3 & 4 \\ 1 & 2 & 3 & 4 \\ 1 & 2 & 3 & 4 \\ 1 & 2 & 3 & 4\end{array}$

For the following questions please circle the number between 1 and 7 that best applies to you

29. How would you rate your overall health during the past week?
1
2
3
4
5
6
7

Very poor

Excellent

30. How would you rate your overall quality of life during the past week?

I

2

3

4

5

6

7

Very poor

Excellent

ENGLISH

4
4
4
4
4
4
4
4
4
4

Copyright 1995 EORTC Quality of Life Group. All rightss reserved. Version 3.0 


\section{Appendix D: Participants' Tracking Sheet}

At the end of each day, write down your total steps for that day according to your pedometer. Don't forget to push reset after you record this number! At the end of each week add each day to get the number of steps you took that week. This number will be the number you report online.

\begin{tabular}{|c|c|c|c|c|c|c|c|c|}
\hline & Monday & Tuesday & Wednesday & Thursday & Friday & Saturday & Sunday & Week Total \\
\hline Week 1 & & & & & & & & \\
\hline Week 2 & & & & & & & & \\
\hline Week 3 & & & & & & & & \\
\hline Week 4 & & & & & & & & \\
\hline Week 5 & & & & & & & & \\
\hline Week 6 & & & & & & & & \\
\hline
\end{tabular}

The pedometer you are going to be using, the Accusplit Eagle 107, is very simple to operate. You simply slip it on to your belt, belt-loop, or the top of your pants. The pedometer will automatically keep track of your steps. At the end of the day, take the pedometer off, unhinge the front case by pushing on the latch that says "open" (this is located on the back of the pedometer above the belt clip). The number on the screen is the number of steps you have taken that day. Write this number down on your tracking sheet, and then push "reset" (the yellow button) this way the pedometer will start at zero the next day.

If you experience any problems with your pedometer please notify Sean Fitzpatrick either by phone: 304-685-2823, or by e-mail: sean.fitzpatrick@mail.wvu.edu. 


\section{Appendix E: Interview Cover Letter}

This is Sean Fitzpatrick and I am running the walking program that you participated in (list dates of individual's participation). I am contacting you because I would like to learn a little more about your experience during the six-week walking study. I am contacting every individual who has gone through the study in hopes of learning more about participant's experience with physical activity during cancer treatment.

The goal of these interviews is to learn more about why individuals were successful or not successful in increasing their physical activity levels. If you think that you may willing to answer a few questions, it should take no longer than twenty minutes, I would ask that you please listen as I read you a paragraph to make sure you understand the nature of these interviews.

***Please know that your responses are confidential and that your participation is completely voluntary. ${ }^{* * *}$ The interviews will be recorded on a digital audio recorder so your responses can be written down to analyze the responses. No identifying information will be collected. The audio files will be password protected and deleted within three years of completion of the project. Only individuals 18 years of age or older are allowed to participate. The West Virginia University Institutional Review Board (IRB) has acknowledgment of this study on file.

Access to the written information will be limited to the research team (myself and Dr. Sam Zizzi) - all of whom are trained in the protection of human subjects and data confidentiality. If you have questions about the study, you may contact me at 304-685-2823 or sean.fitzpatrick@mail.wvu.edu. For information about your rights as a research subject, you may call the Executive Secretary of the WVU Office of Research Compliance at (304) 293-7073.

The interview may take 15-20 minutes depending on your responses. Are you willing to participate?

[If no] I appreciate your time. Good bye.

[If yes] Great! Do you have time now to conduct the interview, or is there a time that is more convenient for you? 


\section{Appendix F: Interview Script}

1) Where were you in the treatment process when you participated in this project?

2) Tell me about the type of physical activity, if any, that you do now on a regular basis?

a. How has this changed since your diagnosis?

3) What has been positive about your experience in this project?

4) What has been difficult about your experience in this project?

5) What do you think you accomplished during this project?

a. What do you wish you had accomplished?

6) What specific techniques did you use to try to raise your step counts?

7) What are some of the things that prevented you from increasing your step counts?

8) What type of changes did you notice because of your involvement in the study?

a. (probe physical - "How about any physical changes?", psychological - "How about any changes in how you were feeling?")

9) What type of physical activity would you recommend to anyone newly diagnosed with breast cancer?

a. (probe walking - "How about walking?”)

10) What can you tell us about your participation in this project that would help us design another study to help women increase their physical activity?

a. (probe walking - "How about walking?")

11) Is there anything else you would like to tell us about your experience participating in this project? 